\title{
Petroacoustic Characterization of Reservoir Rocks For Seismic Monitoring Studies Laboratory Measurement of Hertz and Gassmann Parameters
}

\author{
P. Rasolofosaon ${ }^{1}$ and B. Zinszner ${ }^{1}$ \\ 1 Institut français du pétrole, 1 et 4, avenue de Bois-Préau, 92852 Rueil-Malmaison Cedex - France \\ e-mail: : patrick.rasolofosaon@ifp.fr - bernard.zinszner@ifp.fr
}

\begin{abstract}
Résumé - Caractérisation pétroacoustique des roches réservoirs pour les études de monitoring sismique. Mesure au laboratoire des paramètres de Hertz et de Gassmann - La production des gisements d'hydrocarbures, ou le stockage du gaz dans les couches géologiques, a toujours un effet direct sur le contenu en fluides et sur les pressions de pores, et, par conséquent, sur les propriétés sismiques des roches réservoirs. Dans cet article, nous présentons les méthodes de laboratoire permettant de mesurer l'effet des variations de pression différentielle et de fluide saturant sur les vitesses de propagation des ondes élastiques dans les roches réservoirs.
\end{abstract}

L'effet de pression est facilement mesuré, au laboratoire, par l'intermédiaire du coefficient de Hertz, exposant de la fonction puissance liant la vitesse à la pression différentielle. Il est difficile d'estimer la représentativité des échantillons de carottes ayant subi la brutale relaxation de contrainte causée par le carottage. La comparaison statistique de résultats de mesures sur échantillons de surface et sur échantillons de carottes confirme la réalité de cet endommagement. Les valeurs mesurées au laboratoire sont souvent des valeurs par excès. Elles sont très utiles pour fixer des bornes supérieures à l'effet attendu de la pression différentielle. Cet effet est souvent négligeable dans de très nombreux réservoirs calcaires. Il peut être important dans des réservoirs gréseux peu profonds (stockages souterrains) ou surpressurisés.

L'effet du fluide saturant est quantifié par la formule de Gassmann dont la validité est très généralement vérifiée par l'expérience. Pour utiliser cette formule, il faut connaître certaines caractéristiques élastiques de la roche. Ces modules peuvent être déterminés au laboratoire. Nous proposons une méthode originale et simple dans son principe, basée sur la mesure expérimentale de la relation quasi linéaire prédite par la théorie de Biot-Gassmann, entre le module d'incompressibilité $K_{\text {sat }}$ de la roche saturée et le module d'incompressibilité $K_{f l}$ du fluide saturant.

Dans les grès, lors des expériences de substitution, il faut utiliser des liquides ne perturbant pas les minéraux argileux (et les feldspaths altérés). Hormis le cas des grès parfaitement propres, il est alors très préférable de conserver une saturation irréductible en saumure $\left(S_{w i}\right)$ et donc de travailler en saturation diphasique (saumure/hydrocarbures).

Dans les calcaires, d'où l'argile est le plus souvent absente, les expériences de substitution de fluides sont facilitées par la possibilité de pratiquer des balayages monophasiques par des liquides de module d'incompressibilité très varié. L'avantage induit par cette réelle facilité expérimentale est malheureusement diminué par la difficulté de traitement des signaux qu'entraîne le phénomène de 
« dispersion de cheminement » correspondant à de la diffraction sur des hétérogénéités de dimension non négligeable devant la longueur d'onde. Ces hétérogénéités (liées sans doute à la complexe diagenèse des calcaires) sont omniprésentes mais pas toujours détectables par une étude pétrographique traditionnelle. L'utilisation des vitesses de phases dans le traitement des signaux transmis est le moyen le plus sûr pour contribuer à résoudre cette difficulté. Dans le cas des roches de composition minéralogique simple (calcaire, grès propre), la connaissance du module d'incompressibilité de la matrice solide $K_{\text {grain }}$ fournit un excellent moyen de contrôle des résultats, ce qui facilite beaucoup l'interprétation.

\begin{abstract}
Petroacoustic Characterization of Reservoir Rocks for Seismic Monitoring Studies. Laboratory Measurement of Hertz and Gassmann Parameters - The production of oil and gas reservoirs, or the storage of gas in geological formations, always has direct repercussions on the fluid content and pore pressure, and hence on the seismic properties of reservoir rocks. This article describes the laboratory methods used to measure the effect of variations in differential pressure and saturating fluid on elastic wave propagation velocities in reservoir rocks.
\end{abstract}

The pressure effect is easy to measure in the laboratory, via the Hertz coefficient, exponent of the power function linking the velocity to the differential pressure. It is difficult to estimate the representativity of core samples that have undergone the sudden stress relaxation caused by coring. A statistical comparison of the measurement results on surface samples and core samples confirms the reality of this damage. The values measured in the laboratory are often values from above. They are very useful for setting the upper bounds of the anticipated effect of differential pressure. This effect is often negligible in many limestone reservoirs. It may be high or overpressurized in shallow sandstone reservoirs (underground storage facilities).

The effect of the saturating fluid is quantified by the Gassmann formula, the value of which is usually confirmed by experiment. The use of this formula requires the knowledge of certain elastic properties of the rock. These moduli can be determined at the laboratory. We propose an original method that is also simple in principle, based on the experimental measurement of the quasi linear relation predicted by the Biot-Gassmann theory, between the bulk modulus $K_{\text {sat }}$ of the saturated rock and the bulk modulus $K_{f l}$ of the saturating fluid.

In sandstones, during substitution experiments, the liquids used must not disturb the clay minerals (and weathered feldspars). Apart from the case of perfectly clean sandstones, it is therefore highly preferable to preserve an irreducible saturation of brine $\left(S_{w i}\right)$ and hence to work with two-phase saturation (brine/hydrocarbons).

In limestones, which usually contain no clay, fluid substitution experiments are facilitated by the possibility of single-phase flushing by liquids with highly varied bulk modulus. The advantage procured by this experimental expedient is unfortunately diminished by the difficulty of signal processing caused by the "path dispersion" mechanism corresponding to the scattering on heterogeneities of nonnegligible size compared with wavelength. These heterogeneities (obviously associated with the complex diagenesis of limestones) are omnipresent but not always detectable by a conventional petrographic study. The use of phase velocities in processing transmitted signals is the safest means to help solve this difficulty. In the case of rocks of simple mineralogical composition (limestone, clean sandstone), the knowledge of the bulk modulus of the solid matrix $K_{\text {grain }}$ offers an excellent means to check the results, thereby substantially facilitating interpretation.

\section{INTRODUCTION}

Feasibility studies of seismic monitoring (or repetitive shooting or 4D shooting) are based on modeling the effects of the variations caused by the production in the seismic response of an oil or gas reservoir. Production always has a direct effect on the fluid content of a reservoir, and also, generally, on its pore pressure. It is therefore necessary to know the effect of these two parameters on the seismic properties of the reservoir rock that we want to model.

The effect of pore pressure can only be investigated experimentally in the laboratory if core samples are available.

By contrast, the fluid substitution effect can be quantified by the Gassmann formula, provided the reservoir lithology 
and the elastic moduli ( $P$ and $S$ wave velocities) are accurately known in a state of saturation with a fluid of known bulk modulus and density. If $P$ and $S \operatorname{logs}$ are available in a water saturated reservoir, this effect can be calculated, and many feasibility studies are based on these data. However, it must be pointed out that:

- $S$ logs are not always available, so that this information must be replaced by less accurate PV/SV ratio data;

- rarely in practice is it necessary to substitute a petroleum fluid for water (except for underground storage facilities), so that interest is usually focused on layers where the incompressibility of the saturating mixtures is poorly known (transition zone around the well).

In these two cases, which are merely the simplest examples, the petroacoustic characterization of the reservoir rock is affected by a significant uncertainty, hence the importance of laboratory measurements on core samples, if any. In this article, we propose to describe the laboratory methods allowing this characterization of the pore pressure and fluid substitution effect on the seismic velocities. A complete characterization would also require a study of the effects on attenuation, but for the time being, no method exists for measuring attenuation that is both sufficiently reliable and routinely applicable to core samples. We shall therefore restrict ourselves to the study of velocities.

After discussing the Hertz coefficient, which allows a simple characterization of the pressure effect, we address the fluid substitution effect by describing an original method for estimating the parameters $\left(K_{\mathrm{dry}}, K_{\mathrm{grain}}\right)$ of the Gassmann formula. We emphasize a number of practical aspects associated in particular with the measurement of the ultrasonic wave propagation velocities.

\section{REVIEW OF THE MEASUREMENT OF ULTRASONIC WAVE VELOCITIES}

The laboratory measurement of the propagation velocity of mechanical waves with ultrasonic frequencies $(0.5 \mathrm{MHz})$ becomes complicated when a high degree of accuracy and rigor is desired. We shall merely review some general information that is useful for our discussion, referring the reader seeking greater detail to Bourbié et al. (1987) or Mavko et al. (1998). This measurement is only easy in homogeneous materials at the scale of the wavelength and perfectly elastic, i.e. in which velocity is independent of the wave frequency and where the shape of the signal is not significantly altered during propagation. Thus in aluminum (which exhibits quasi perfect elasticity), the propagation velocity can be calculated by regression, by measuring the transit time of the signal transmitted by a piezoelectric transducer, on specimens of different lengths. Highly accurate results (uncertainty of a few thousandths) are thus easily obtained. This is the way in which the standards used for comparative measurements are characterized.

\subsection{Problems: Anelasticity and Heterogeneity}

\subsubsection{Anelasticity: Signal Distortion}

If a material is not perfectly elastic, which is the case of rocks, the acoustic signal used for the measurements, which is not a single-frequency signal, is distorted during propagation by selective filtering of the high frequencies. For propagation over different distances, it is theoretically not possible in the time domain, to compare it to itself or to an elastic reference.

\subsubsection{Heterogeneity: Scattering (Path Dispersion)}

If the material is not homogeneous at wavelength $(\lambda)$ scale, which is frequently the case when ultrasound (centimetric $\lambda$ ) is used, the legitimacy of the measurement may be put into question. The most significant consequence on the velocity measurement corresponds to a scattering effect which is qualified as "path dispersion" (see for example Cadoret et al., 1995). This is simply (and perhaps somewhat falsely) explained by stating that a part of the acoustic energy (usually small) takes faster or slower paths, associated with the heterogeneities of the rock. As opposed to the case of a homogeneous medium, the acoustic signal propagating in a heterogeneous medium undergoes a time defocusing: a part of the energy arrives before (precursors) and after (secondary arrivals, codas, etc.) the "main energy packet". The arrival time of the precursors is measured by the first break picking. This path dispersion can be found even in rocks with a small "petrographic" grain size distribution compared with wavelength, and which could be presumed to be immune to scattering mechanisms. This is because the "physical" grain size distribution (impedance), which is paramount for wave propagation, may be quite different from the "petrographic" grain size distribution. This mechanism is common in limestone rocks (see for example Lucet and Zinszner, 1992).

\subsection{The Different Methods for Measuring Velocities}

\subsubsection{Measurement by First Break Picking: "First Break Velocity"}

The first break velocity corresponds to the simplest way to measure a velocity. It consists in picking the arrival time of the start (first break) of an acoustic signal which has propagated in the medium. If we also have a standard in which the propagation time ("transit time") of the signal is very accurately known, it is easy, by subtraction, to accurately calculate the transit time in the sample investigated, and hence the propagation velocity. If the signal that has traversed the sample is very close to the one that has traversed the standard, the measurement uncertainty factors are limited to measurements of sample length and transit time on the oscilloscope, and this uncertainty is very low. On the 
other hand, if the signal is distorted for the reasons stated earlier, the first break picking may be very inaccurate and the measurement loses all physical meaning.

In practice, picking is always easier for $P$ waves which, by definition, are the first to appear on the very low background noise. By contrast, it is sometimes very difficult to distinguish the precise arrival of the $S$ wave train ( $S$ first break) on the noise associated with reflected $P$ waves and the different $P-S$ converted waves.

Measurement by first break picking is especially inaccurate in case of path dispersion, the case in which the early arrivals can falsely increase the velocities by several percentage points.

\subsubsection{Measurement by Signal Correlation: "Correlation Velocity"}

As opposed to the first break picking method, where the only point selected on the signal sets the velocity value, in the correlation method, the entire signal selected is taken into account to determine the velocity. In fact, by time correlation, this signal is compared with a reference signal of known transit time. The lag time corresponding to the best possible correlation serves to calculate the transit time associated with the signal analyzed. Here also, the result is strongly conditioned by the morphological proximity of the signal and of the reference. If the shapes of the two signals differ significantly, the result is highly debatable. The correlation method is very useful to perform numerous automated measurements, using a limited number of signals selected for reference and whereof the velocity is carefully measured. It is also very useful for measurements of $S$ waves, by overcoming the problem of $S$ first break picking.

\subsubsection{Measurement by Phase Spectrum Ratio: "Phase Velocity"}

If we consider the frequency spectrum of the phase of the signal analyzed and of the reference sample, it is easy to calculate the phase difference between these two signals (after having "unwrapped" these phases, to avoid problems of phase spectrum and discontinuity). The phase difference $(\Delta \varphi) v s$ frequency $(\omega)$ relation will be approximately linear over the frequency intervals for which the quality factor $Q$ (viscoelastic attenuation) remains constant. This assumption of constant $Q$ is often found to be confirmed on the frequency passbands of common ultrasonic transducers. Since the phase velocity in the reference is also known, it is easy to calculate the phase velocity in the sample analyzed, from the slope of the line $\Delta \varphi v s \omega$. This method yields excellent results as long as the acoustic signal is of good "quality". Hence it demands the use of damped transducers, and this could sometimes complicate the construction of measurement systems under confining pressure. Naturally, the result obtained is conditioned by the quality of the spectra calculated, i.e. in practice, by the way in which the portion of the signal analyzed has been selected, making this phase velocity method slightly less ideal than other methods for automated measurements. For further detail on this technique, the reader can usefully consult the thesis of Tarif (1986).

\section{EFFECT OF THE VARIATION IN DIFFERENTIAL PRESSURE ON THE ELASTIC WAVE PROPAGATION VELOCITIES: HERTZ COEFFICIENT}

\subsection{Definition of the Hertz Coefficient}

In rocks, the elastic wave propagation velocities depend on the differential pressure applied to the sample (the differential pressure is the difference between the confining pressure and the pore pressure). In certain cases, the pressure effect is very strong. The cause of this dependence is well known (Birch 1960; Walsh and Brace, 1966): above all, it is due to the effect of the ubiquitous mechanical microdefects (microcracks, grain boundaries, twins, etc.) which close under the effect of the differential stress and thereby increase the rigidity of the material.

Experimentally, it is found that the relation of velocity $(V)$ to differential pressure $\left(P_{\text {eff }}\right)$ is of the power function type. Figure 1 shows the results corresponding to the mean of the first break velocity measurements taken on some twenty samples of Vosges sandstone ("Vosgian" variety) saturated with brine. The different samples taken alongside each other in the same block have sufficiently similar acoustic properties for the mean of the values to yield a very reliable velocity/ pressure curve. It may be observed in this figure that the formula $V=k P^{h}$ is perfectly confirmed for P waves and very satisfactorily so for $S$ waves. The slight fluctuations in the relation for $S$ waves can be attributed to the uncertainties of the first break picking.

Hertz demonstrated by calculation that in a stack of isodiametral spheres, in elastic contact, velocity varied with the pressure according to a power law, and that for $P$ waves, the exponent was $1 / 6$. The exponent $\mathrm{h}$ is therefore called the "Hertz coefficient".

To estimate the effect of a variation in differential pressure in the reservoir on the velocities, it suffices to determine the Hertz coefficient which can be used to easily calculate the proportionality factor of the power law and apply it to the values supplied by the sonic log.

\subsection{Measurement of the Hertz Coefficient}

\subsubsection{Laboratory Measurement}

It is particularly easy to measure the Hertz coefficient on a sample because it suffices to measure the variation in 

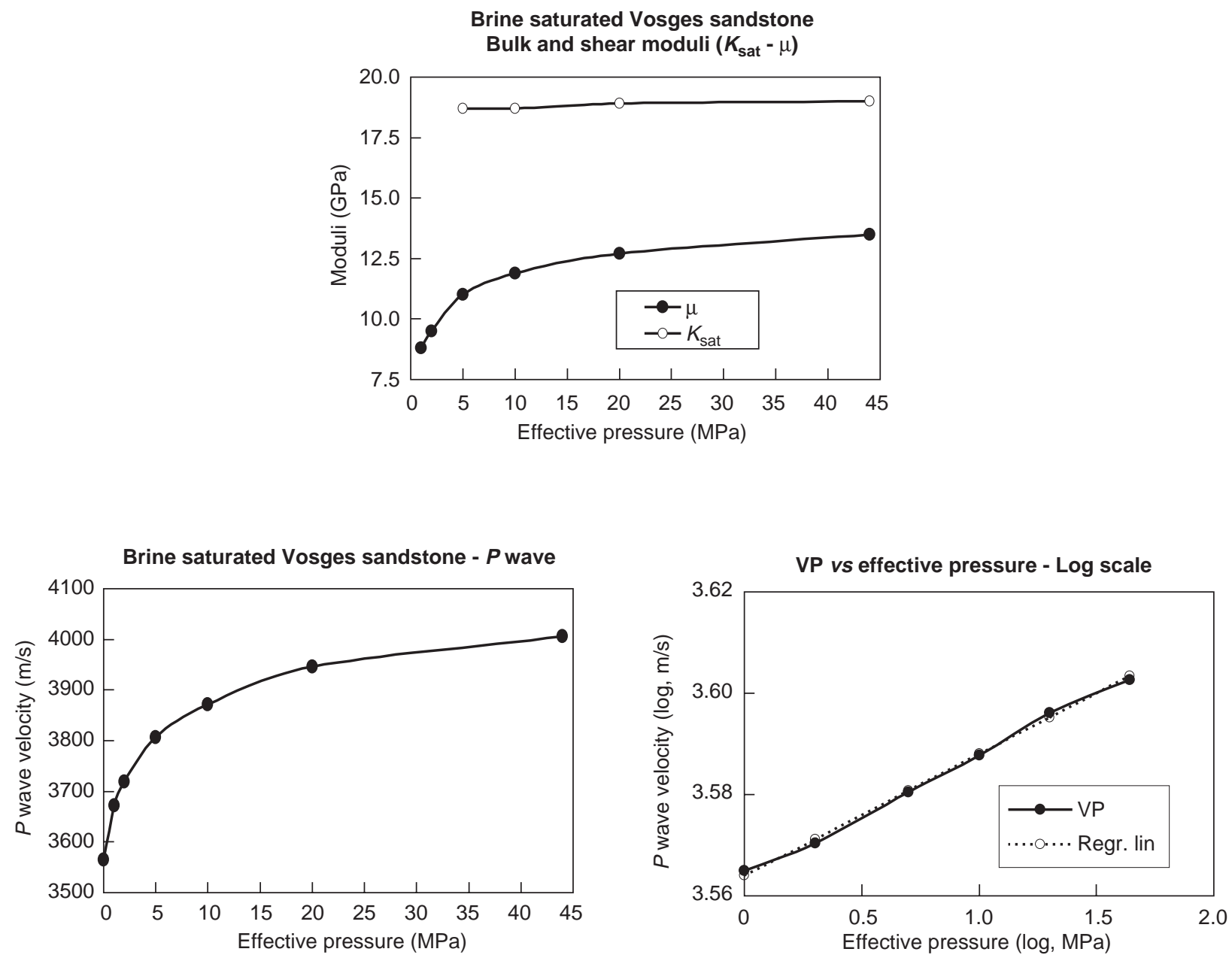

Brine saturated Vosges sandstone - $S$ wave

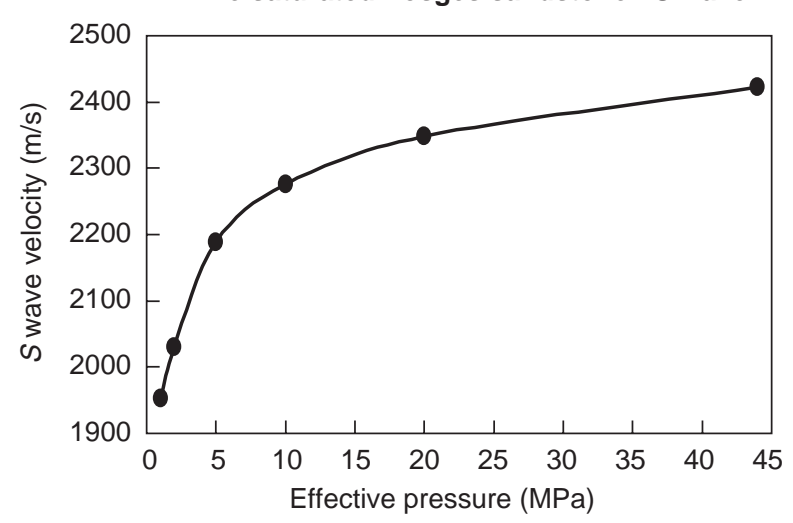

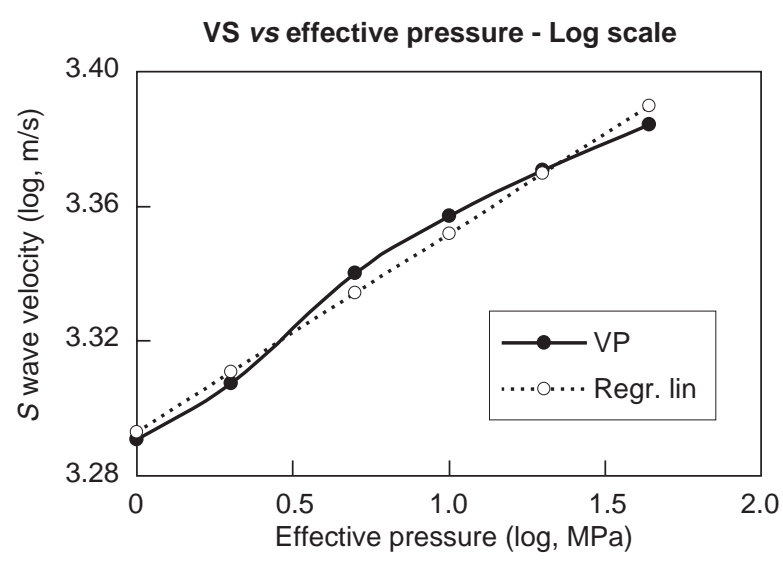

Figure 1

Velocity-differential pressure relation in Vosges sandstone. 
velocity under the effect of the differential pressure and to calculate the slope of the linear relation $V v s P_{\text {eff }}$ in bilogarithmic axes. It is especially important to accurately measure a relative variation in velocity, which corresponds to the easiest case. It is customary to use the correlation velocity values calculated "in cascade" as follows.

The signal recorded at the maximum differential pressure is taken as the reference signal, i.e. exhibiting the weakest attenuation and hence the surest velocity measurement by first break picking. The velocity for the next lower pressure level is calculated by correlation, it then serves as a reference and so on. Note that the only velocity introduced a priori is the velocity at maximum pressure. Note also that in the case of media where attenuation varies significantly with differential pressure (sandstone with grain boundaries, for example), this "descending" correlation method leads to an underestimation of the velocities at low differential pressure (strong attenuation) and hence to a certain overestimation of the Hertz coefficient.

\subsubsection{Representativity of Core Measurements}

To the best of our knowledge, no method is currently available for measuring the Hertz coefficient in situ, and this obliges us to rely completely on laboratory measurements, raising the problem of the mechanical representativity of the cores.

During coring operations, the rock undergoes sudden variations in stress (relaxation). The mechanical damage sustained by the rock on this occasion can be increased by the alteration of certain minerals (mainly clays) under the effect of drying. It is therefore legitimate to question the mechanical representativity of the cores. It is considered that the restoration to confining pressure (sometimes to values higher than those prevailing in the reservoir) helps to offset this effect for velocities, for example. But what of the Hertz coefficient which precisely characterizes the pressure sensitivity?

Some experimental investigations (for example Ness $e t$ al., 2000) highlight this damage to the samples. We propose another approach, consisting of a statistical analysis of the values of the Hertz coefficient measured on cores and on surface outcrop samples. The surface samples have undergone a very slight decompression (at geological time scale) and have therefore been protected from this cause of damage. We have a database (unpublished) containing the values of the ultrasonic $P$ and $S$ velocities taken from the public literature or IFP. A rapid study (Fig. 2) shows that for sandstone samples, the Hertz coefficients are statistically substantially higher for samples taken from cores compared with samples taken from outcrops, and this is valid for $P$ waves and $S$ waves alike. This offers some rough but undeniable evidence of the effect of core damage on the Hertz coefficient.

\subsection{Values of Hertz Coefficients in Rocks}

\subsubsection{Limestone/Sandstone Contrast}

The contrast of the Hertz coefficient between limestone and sandstone is striking. In Figure 2, it may be observed that more than 3/4 of the limestones plotted have a Hertz coefficient lower than the minimum of the sandstones, both for $P$ and $S$ waves, so that there is practically no overlap between the histograms. This quantitatively illustrates the well-known general observation: velocities in limestones are much less sensitive to differential pressure than in sandstones. There is a simple reason for this: in limestones, mechanical microdefects are much less frequent than in sandstones, because the calcite cement can be formed much faster. The data available on dolomites are too rare to derive a statistical idea, but the Hertz coefficients appear to be much higher in saccharoid dolomites (inter-crystalline boundaries).

\subsubsection{Comparison of $\boldsymbol{P}$ and $S$ Hertz Coefficients in Sandstones}

Figure 1 shows that the bulk modulus $K_{\text {sat }}$ of Vosgian sandstone is practically invariable with differential pressure. The slight fluctuations at the low pressures fall within the experimental uncertainty margin. The entire differential pressure effect corresponds to the variation in the shear modulus. This observation is a common one in clean or very slightly argillaceous sandstones. However, in representative argillaceous sandstones, the bulk modulus may vary substantially with differential pressure.

This at least partial insensitivity of $K_{\text {sat }}$ to the differential pressure explains the distribution of the $S$ Hertz/PHertz ratios in sandstones, where the modal value is around 1.5 (Fig. 2).

\subsubsection{Factors Influencing the Hertz Coefficient in Sandstones}

We shall only address the case of sandstones, because the Hertz effect is marginal in limestones. The porosity-Hertz coefficient relation is very vague (Fig. 2). A slight correlation exists, as demonstrated by the gently sloping regression lines, both for outcrop and core samples. Porosity is not a determining factor, which seems normal since mechanical microdefects contribute virtually nothing to the total porosity of reservoir rocks (the situation is obviously quite different for compact rocks).

Micas appear to play a major role in certain sandstones. Even very small crystals, in small quantities, cause high Hertz coefficients. Our observations mainly concern core samples. It would be interesting to determine the real consequences of the alteration/relaxation of the micas on this effect, by measurements on surface samples.

\subsection{Conclusion on the Differential Pressure Effect}

We have seen that it is easy to measure the Hertz coefficient in the laboratory, but that the application of these laboratory 
Compressional wave - Limestone (48 samples, including 16 outcrops)

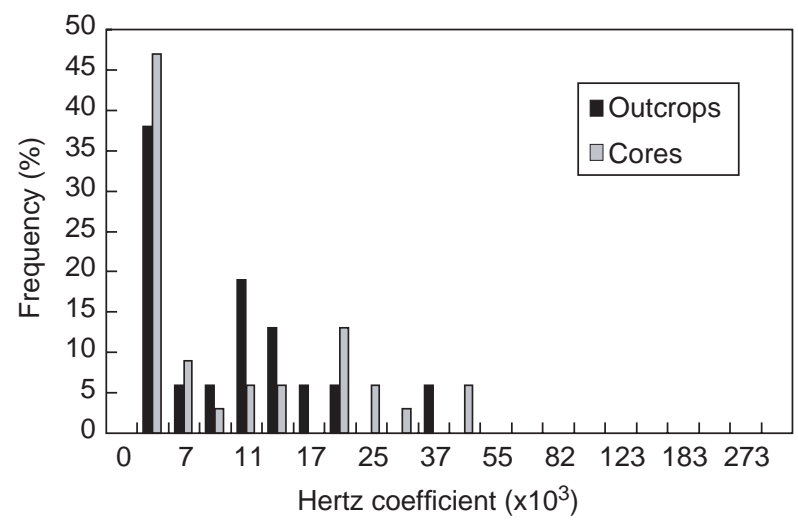

Shear wave - Limestone

(48 samples, including 16 outcrops)
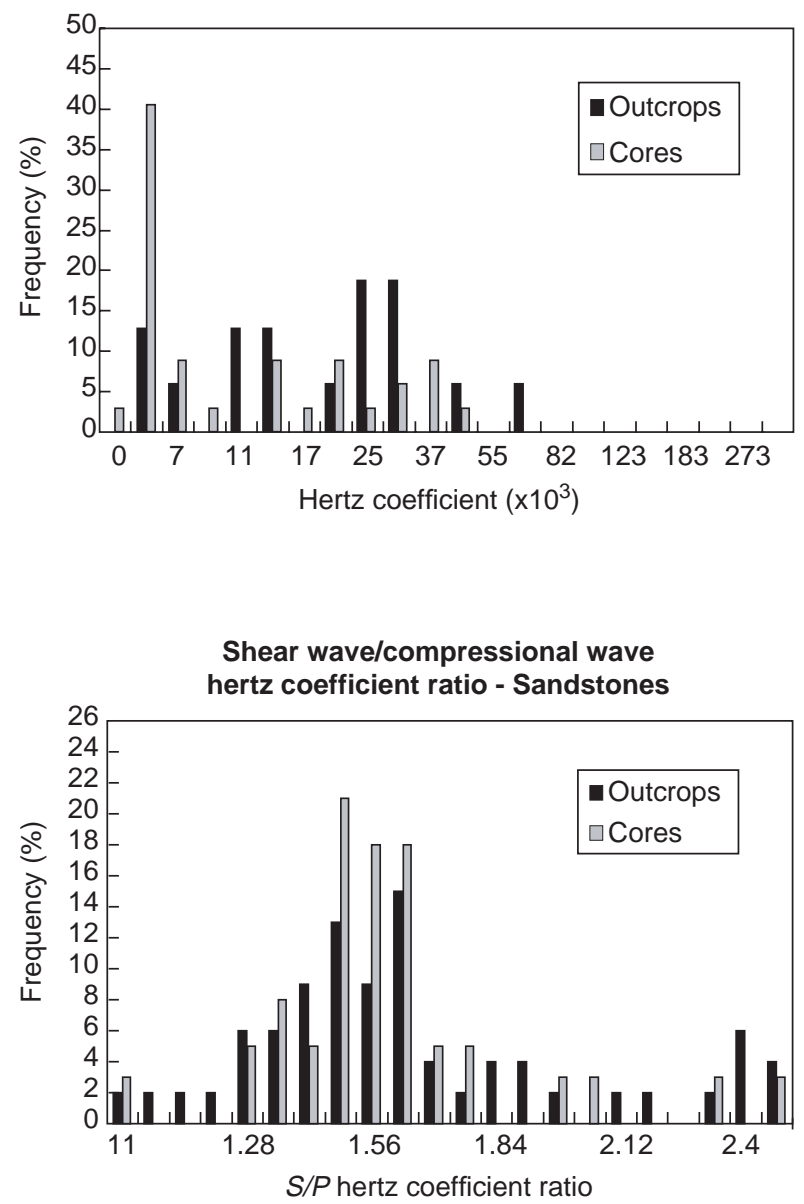

Compressional wave - Sandstone (86 samples, including 48 outcrops)

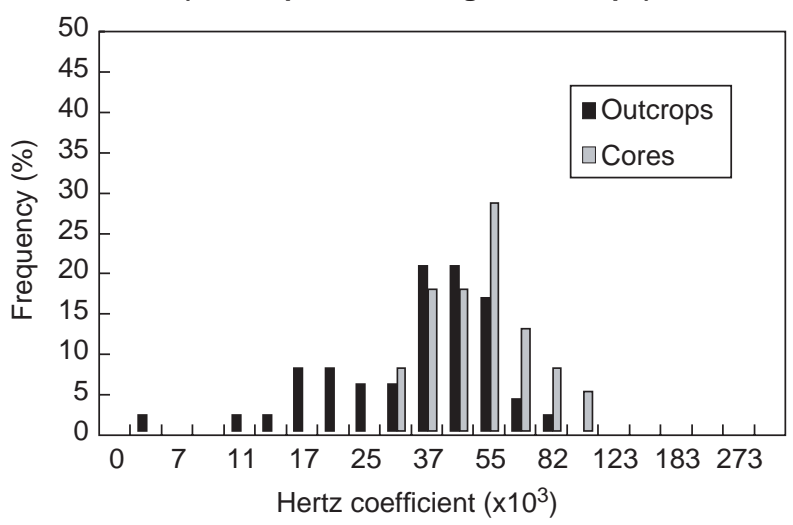

Shear wave - Sandstone (86 samples, including 48 outcrops)

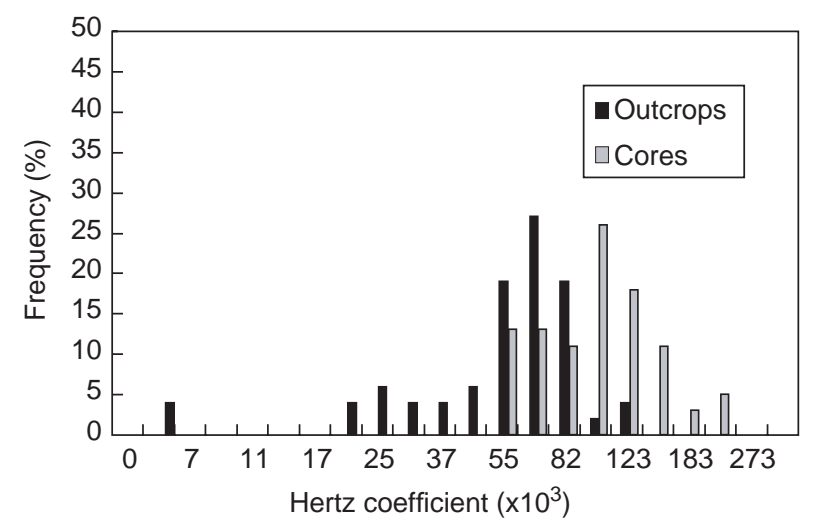

Sandstones porosity 4 to $22 \%$

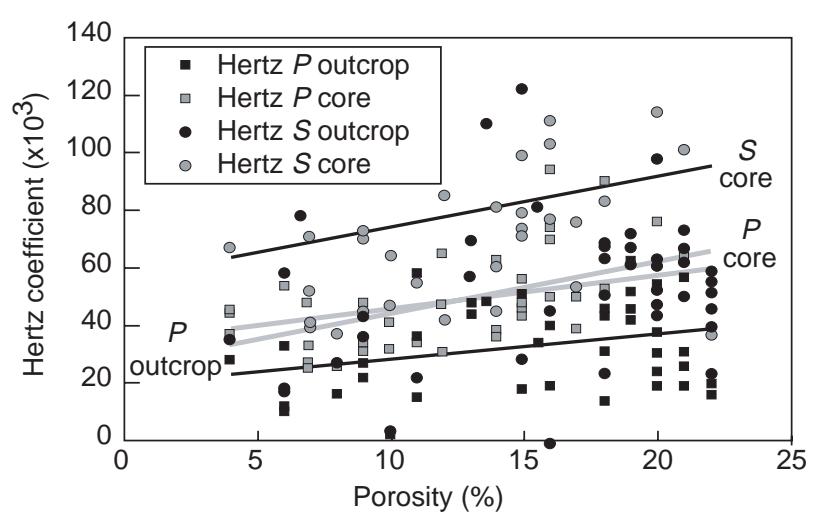

Figure 2

Distribution of $P$ and $S$ Hertz coefficients in sandstones and limestones sampled in outcrops and in cores. 
results to reservoir conditions is subject to caution, due to the very probable effects of stress relaxation and the alteration of certain minerals. The values measured in the laboratory are usually values from above and never values from below. However, they are very useful because they help to set the upper bounds of the anticipated effect of the differential pressure.

It can also be shown that this effect can be ignored in many limestone reservoirs. It only becomes really important in two cases:

- reservoirs with low geostatic stress, i.e. shallow reservoirs such as underground storage facilities;

- overpressurized sandstone reservoirs.

\section{EFFECT OF FLUID SUBSTITUTION ON ELASTIC WAVE PROPAGATION VELOCITIES: GASSMANN PARAMETERS}

\subsection{The Gassmann Formula and its Linear Approximation in $f\left(K_{f f}\right)$}

The Gassmann formula, used in geophysical prospecting to predict the effect of a variation of saturated fluid on the seismic velocities, has been the subject of many publications. We refer the reader interested in a detailed study to Bourbié et al., 1987 or Mavko et al., 1998. We shall restrict ourselves here to a number of points useful for the rest of our exposé.

Gassmann (1951) calculated the difference in elastic modulus, for a quasi static load, between a drained porous medium (i.e. in which the saturating fluid pressure remains unchanged during the mechanical loading) and the same undrained medium, in which local variations in fluid content are nil during mechanical loading. The Gassmann theory assumes a continuous and homogeneous porous medium, but does not imply any condition on the pore geology. The application of the Gassmann formula to wave propagation (dynamic case) requires the frequency to be sufficiently low for the variation in pressure of saturating fluid induced by the passage of the wave to be uniform in the porous medium (no gradient).

The Gassmann formula links the drained $\left(K_{\text {dry }}\right)$ and undrained $\left(K_{\mathrm{sat}}\right)$ bulk moduli by means of parameters:

- specific to the porous medium: porosity $\phi$ and incompressibility of the mineral forming the grains $\left(K_{\text {grain }}\right)$;

- specific to the saturating fluid: $K_{f l}$, bulk modulus of the fluid.

The drained bulk modulus $\left(K_{\mathrm{dry}}\right)$ is associated with that of the rock saturated with gas under low pressure (dry rock). It is important to note that experimentally, the modulus measured on a dry rock may be quite different from the modulus $K_{\text {dry }}$ used by Gassmann (see below).
A practical expression of the Gassmann formula includes the Biot coefficient $\beta$ (1941):

and

$$
\begin{gathered}
K_{\text {sat }}=K_{\text {dry }}+\beta^{2} M, \text { with } \\
\beta=1-\left(K_{\text {dry }} / K_{\text {grain }}\right)
\end{gathered}
$$

$$
M^{-1}=\left[(\beta-\phi) / K_{\text {grain }}\right]+\phi / K_{f l}
$$

Note that since the fluids are no-shear materials, the drained $\left(\mu_{\text {dry }}\right)$ and undrained $\left(\mu_{\text {sat }}\right)$ shear moduli are equal.

In the above equation, it may be observed that the first term of the expression of $M^{-1}$ is often much smaller than the second, because $K_{\text {grain }}$ is always much higher than $K_{f l}$. If the first term is ignored, we obtain a very simple equation:

$$
K_{\text {sat }} \approx K_{\text {dry }}+\left(\beta^{2} / \phi\right) K_{f l}
$$

The error thus committed can be estimated by calculating the difference between the two equations for values corresponding to $K_{\text {dry }}$ and $K_{\text {grain }}$ parameters of limestones and sandstones (Rasolofosaon and Zinszner, 2002). For limestones (high $K_{\text {grain }}$ of calcite) with more than $20 \%$ porosity, if common fluids are considered, the difference between the result of the simplified formula and that of the complete expression remains far below $5 \%$, in terms of elastic modulus (and hence $2.5 \%$ in terms of velocity). For porous sandstones, it is around 5\%, and hence remains negligible compared with the experimental uncertainties. It is only in the case of a low porosity reservoir (10\%), especially sandstone, that the difference between the two expressions can become significant.

\subsection{Principle of the Measurement of Gassmann Coefficients}

The simplified formula above serves to consider a simple experimental measurement of the Gassmann parameters (although much more complicated, the procedure remains valid if the complete formula is used). In fact, by substituting fluids of variable incompressibility in a porous medium whereof the compressional $(V p)$ and shear $(V s)$ wave propagation velocities are measured, it is easy to calculate $K_{\text {sat }}=\rho\left[V p^{2}-(4 / 3) V s^{2}\right]$ where $\rho$ is the density of the rock. The simplest and most useful expression of our measurements is hence the graph $K_{\text {sat }} v s K_{f b}$, which, in the general case in which the Gassmann formula is clearly confirmed, is a line with $Y$-axis intercept value equal to $K_{\text {dry }}$ and with slope $\beta^{2} / \phi$.

Since the porosity is always very accurately known, it is easy to calculate the Biot coefficient and derive the experimental value of $K_{\text {grain }}$. It is shown that the value thus obtained for $K_{\text {grain }}$ is very sensitive to the experimental uncertainties, because the least fluctuation on the slope of the regression $K_{\text {sat }} v s \quad K_{f l}$ causes a high variation in the value $K_{\text {grain }}$. The type of rock and hence the order of magnitude of $K_{\text {grain }}$ is also 
known. $K_{\text {grain }}$ is sometimes known a priori accurately for monomineral rocks (e.g. limestones). But even if some uncertainty exists (as in the case of argillaceous sandstones), the calculated value of $K_{\text {grain }}$ is an excellent means to check the quality of the experimental results.

It is much easier to accurately measure the relative variations in velocities rather than the absolute values. For a given level of differential pressure (i.e. for a relation $K_{\mathrm{sat}} v s K_{f l}$ ), the velocity variations are therefore calculated for the different saturations from a saturation state selected as a reference. However, it is important to note that the accuracy on the absolute velocity of this reference has significant consequences on the accuracy obtained on $K_{\text {dry }}$ and $K_{\text {grain }}$. It is therefore important to measure the absolute $P$ and $S$ velocities of this signal selected as a reference, as accurately as possible.

The method described above offers the advantage of presenting an inversion that takes account of all the experimental points and does not require any a priori assumption about the type of mineral concerned ( $K_{\text {grain }}$ ). If $K_{\text {grain }}$ is known (limestone rocks, for example), it is obviously possible directly to calculate $K_{\text {dry }}$ for each experimental value of $K_{\text {sat }}$ by using a complete form of the Gassmann formula, and provide a statistical expression of the different values of $K_{\text {dry }}$ thus obtained.

\subsection{Acquisition of $P$ and $S$ Ultrasonic Signals and Fluid Substitution}

\subsubsection{Experimental System}

The measurement cell corresponds to a standard device for measurement under confining pressure (Fig. 3). The rock sample, $40 \mathrm{~mm}$ in diameter and 40 to $80 \mathrm{~mm}$ in length, is placed in a Viton sheath which partly covers the two measurement heads each containing an ultrasonic transducer. In our experiment, we use double $P$ and $S$ transducers (two half-moon ceramics) yielding very high quality signals (Fig. 4). Equipped in this way, the cell is filled with oil for confinement. If the flexible sheath effectively transmits the hydrostatic confining pressure, this does not rigorously apply for the rigid measurement heads. In practice, however, the assumption of hydrostatic confinement is not seriously jeopardized. In our experiment, the maximum permissible confining pressure is $70 \mathrm{MPa}$ (around $10000 \mathrm{psi}$ ).

"Electrical wall penetrations" help to connect the internal measurement heads to a conventional external device for processing and recording the ultrasonic signals. This device essentially consists of:

- an electric pulse transmitter used to excite the transmitting ceramic;
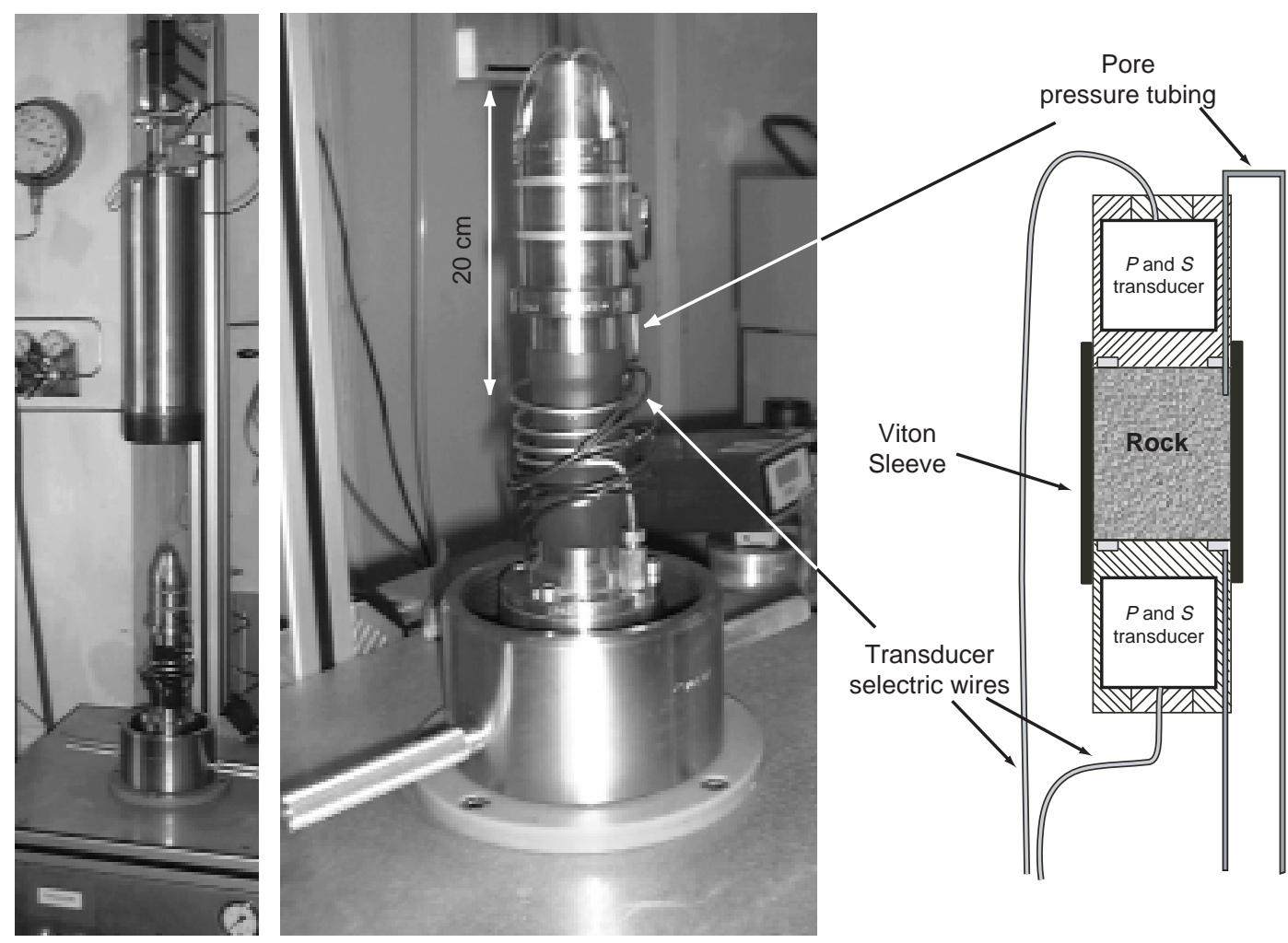

Figure 3

Photograph and diagram of the cell for acoustic measurement under confining pressure. 
Sintered quartz, $P$ wave, $10 \mathrm{MPa}$, normalized amplitude, common first break

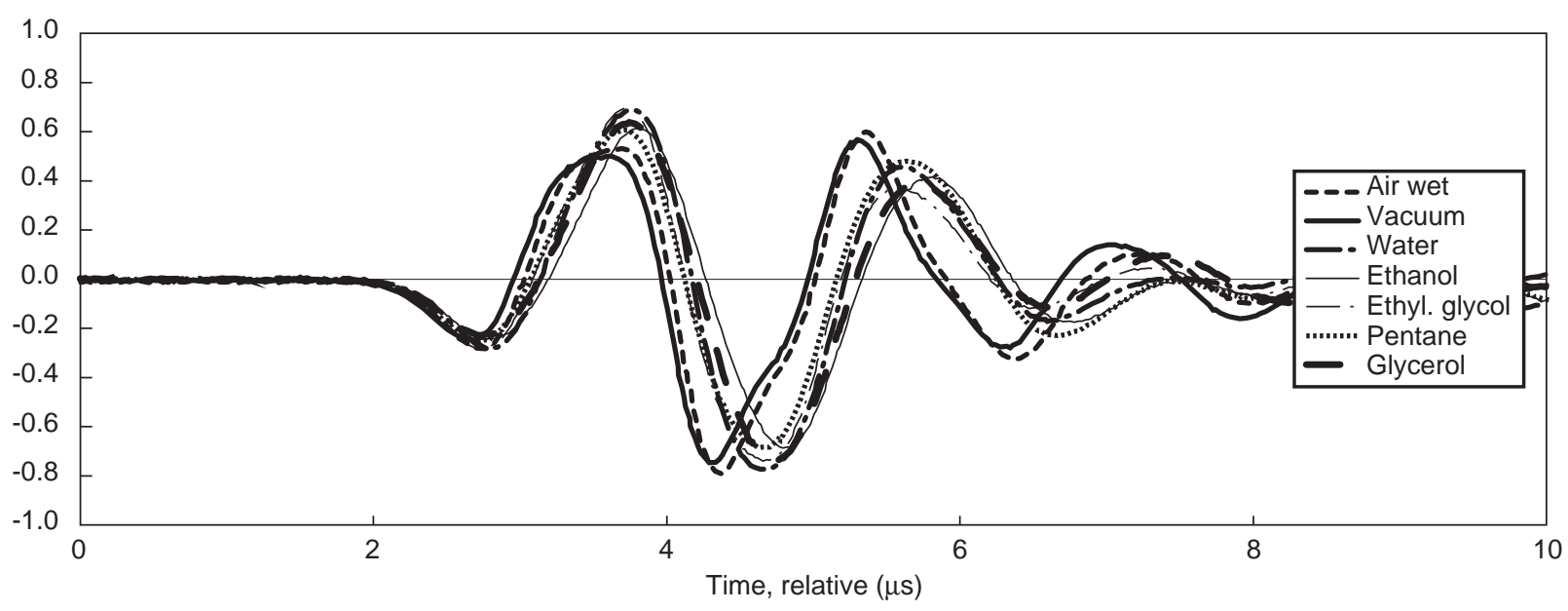

Sintered quartz, $S$ wave, $10 \mathrm{MPa}$, normalized amplitude, common first break

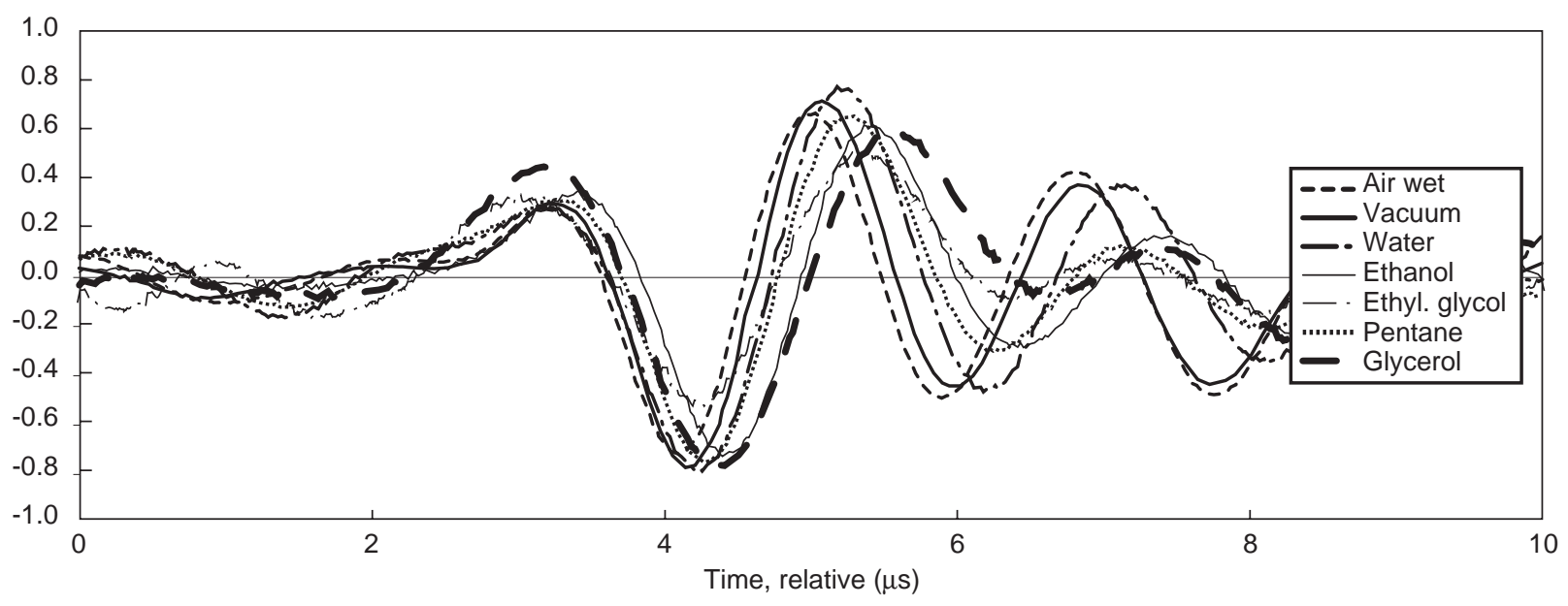

Bulk modulus from first break picking
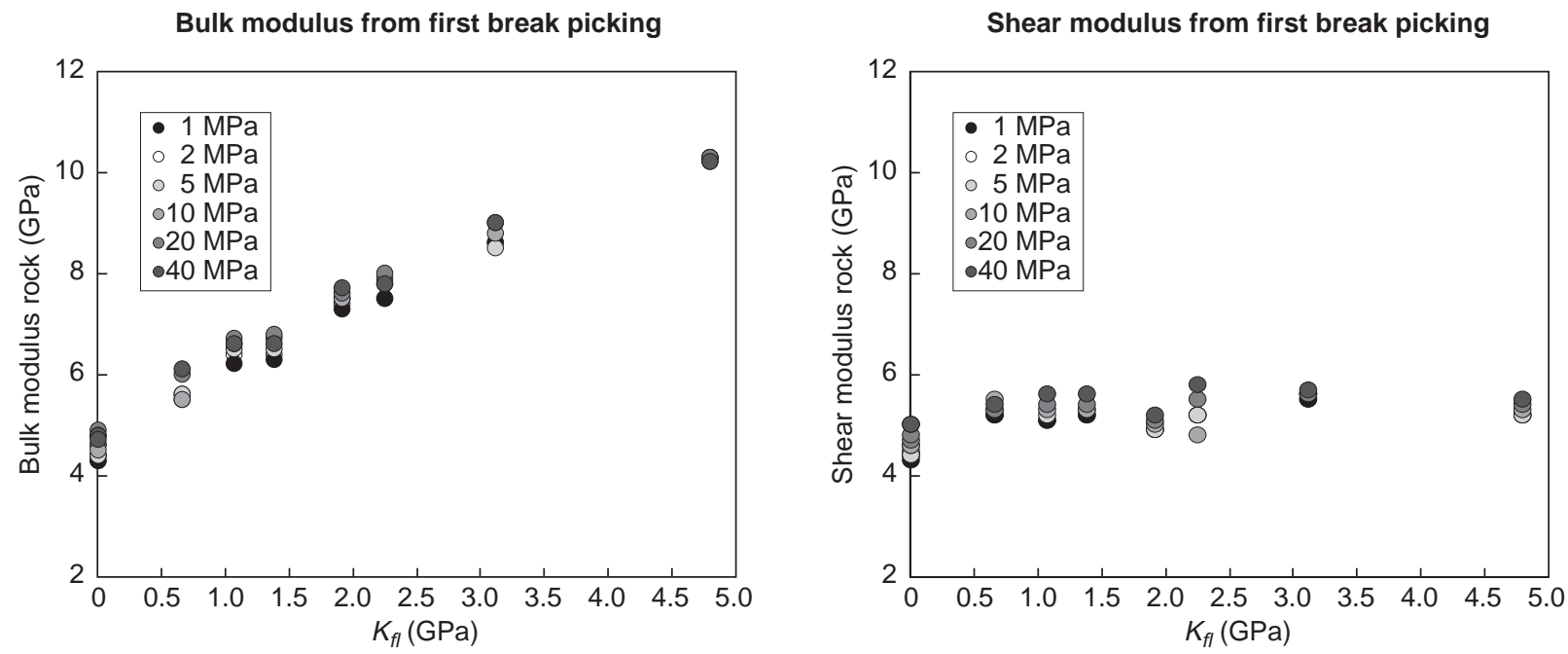

Figure 4

Sintered quartz: $P$ and $S$ waves propagated during a fluid substitution experiment. Relations $K_{\text {sat }}=f\left(K_{f l}\right)$ and $\mu=f\left(K_{f l}\right)$. 
- a conditioner/amplifier of the electric signal transmitted by the receiving ceramic;

- an oscilloscope connected to a PC used to process and record the signals.

\subsubsection{Saturation Methods for Fluid Substitution}

The basic principle of our experiment is to measure the bulk modulus of the rock (in practice, to measure the $P$ and $S$ wave velocities), for saturation states with fluids of varied bulk modulus $\left(K_{f l}\right)$. To obtain the best possible regression line, it is important to use the series of fluids exhibiting the widest variety of $K_{f l}$. Table 1 shows that liquids routinely used in the laboratory help to obtain a variation in $K_{f l}$ by a factor of 7 (between 0.7 and $4.8 \mathrm{GPa}$ ).

However, all these liquids cannot be used without caution, because two experimental requirements must be met:

- To achieve good single-phase saturation by miscible displacement, the succession of fluids must be selected in an order such that the next is miscible with the previous one. This does not raise any real experimental problem.

- It is absolutely important for the saturating fluid not to interact with certain fractions of the rock matrix. This is a crucial requirement. None of the liquids in Table 1 interact with calcite or dolomite. In principle, they can accordingly be used for the study of calcareous rocks. However, some of them react strongly with clays. Hence a different technique must be used for sandstones which, with few exceptions, always contain an argillaceous fraction whose importance for the mechanical properties may be very high (and not necessarily proportional to the volumetric scale of this fraction).

However, it is first necessary to clarify the specific problem raised by the state of saturation with gas under low pressure.

\section{Saturation State with Air or "Vacuum"}

The saturation state with air is basically a very interesting case because the $K_{f l}$ of the saturating fraction is zero. This is in fact unfortunately untrue because in a terrestrial atmosphere, a "dry" rock always contains adsorbed water which can have a considerable influence on the capillary forces at the grain boundaries. These capillary forces alter the rigidity of the rock in a manner that is impossible to integrate in a Gassmann type approach, and the consideration of the moduli in such a saturation state can substantially distort the results. To minimize these particular capillary effects, the rock must have a sufficiently high moisture content (saturation of several percent?).

In practice, we shall consider two specific saturation states.

- Saturation with wet air: before its loading in the cell, the sample has been stored for a long time in an enclosure with $100 \%$ relative humidity, at ambient temperature. In a first analysis, it can be considered that the capillary effects, discussed above, are minimized.

- "Vacuum" saturation: before the first saturation with liquid (water or brine) and to ensure proper saturation, the

TABLE 1

Properties of some liquids used in the experiments, listed by increasing values of $K_{f l}$

\begin{tabular}{|c|c|c|c|c|c|c|c|c|}
\hline Liquid & $\begin{array}{c}K_{f l} \\
(\mathrm{GPa})\end{array}$ & $\begin{array}{l}\text { Density } \\
\left(\mathrm{kg} / \mathrm{m}^{3}\right)\end{array}$ & $\begin{array}{c}\text { Viscosity } \\
\text { (cP) }\end{array}$ & $\begin{array}{c}\text { Velocity } \\
(\mathrm{m} / \mathrm{s})\end{array}$ & $\begin{array}{c}\text { Impedance } \\
(\mathrm{kPa} \cdot \mathrm{s} / \mathrm{m})\end{array}$ & $\begin{array}{l}\text { Misc. } \\
\text { water }\end{array}$ & $\begin{array}{l}\text { Misc. } \\
\text { ethanol }\end{array}$ & $\begin{array}{c}\text { React. } \\
\text { with clay }\end{array}$ \\
\hline Pentane & 0.72 & 625 & 0.25 & 1073 & 671 & No & Yes & \\
\hline Heptane & 0.88 & 683 & 0.4 & 1135 & 775 & No & Yes & \\
\hline Hexane & 0.9 & 675 & 0.3 & 1155 & 780 & No & Yes & \\
\hline Ethanol & 1.12 & 795 & 1.2 & 1187 & 944 & Yes & & Yes \\
\hline Soltrol & 1.16 & 752 & 1.5 & 1242 & 934 & No & Yes & \\
\hline Kerosene & 1.4 & 804 & & 1320 & 1061 & No & Yes & \\
\hline Bromoform $75 \%$ ethanol & 1.55 & 1720 & & 950 & 1634 & No & Yes & $?$ \\
\hline Trichlorethylene & 1.73 & 1461 & & 1088 & 1590 & No & Yes & $?$ \\
\hline Albelf & 1.9 & 863 & 170 & 1484 & 1281 & No & Yes & \\
\hline Polyal & 1.92 & 845 & 1100 & 1507 & 1273 & No & Yes & \\
\hline Ethanol (40\%) ethy. gly.) & 2.11 & 957 & 5 & 1485 & 1421 & Yes & Yes & Yes + \\
\hline Water & 2.25 & 1000 & 1 & 1500 & 1500 & & Yes & Yes + \\
\hline Brine $25 \mathrm{~g} / \mathrm{l}$ & 2.3 & 1020 & 1 & 1502 & 1532 & Yes & Yes & \\
\hline Bromoform & 2.45 & 2800 & & 944 & 2596 & No & Yes & $?$ \\
\hline Aniline & 2.9 & 1019 & 5 & 1687 & 1719 & No & Yes & Yes + \\
\hline Ethylene glycol & 3.23 & 1112 & 19 & 1704 & 1895 & Yes & Yes & Yes + \\
\hline Glycerol & 4.8 & 1263 & 1500 & 1949 & 2462 & Yes & & Yes + \\
\hline
\end{tabular}


sample is deaerated under vacuum (generally at least overnight). In this saturation state, it can be considered that the remaining water is located in the thinnest meniscii where the capillary forces are especially high. The results in this saturation state are normally never taken into account in calculating the petroacoustic parameters.

Note also that the proper value of $K_{\text {dry }}$ to be used in the Gassmann formula does not correspond to the bulk modulus of the dry rock but to the experimental limit of $K_{\text {sat }}$ as $K_{f l}$ tends toward zero, i.e. the $Y$-axis intercept value of the curve $K_{\text {sat }}=f\left(K_{f l}\right)$.

\section{Single-Phase Saturation for Carbonates}

For calcareous rocks, in which the matrix does not react with any of the liquids listed in Table 1, it is easy to draw up a protocol of miscible displacements making it possible to have a satisfactory range of $K_{f l}$. A very simple series to be used is, for example: water, ethylene glycol, ethanol, pentane. The very high viscosity of glycerol makes its use problematic for rocks with low or average permeability.

Note also that in all cases, the measurements are taken with a pore pressure of about $1 \mathrm{MPa}$ (note that the important petrophysical parameter is the differential pressure, which is the difference between the confining pressure and the pore pressure). This pore pressure helps to eliminate the few residual bubbles of air or vapor, which sometimes persist at atmospheric pressure and have serious consequences on the $K_{f l}$ of the saturating liquid.

\section{Two-Phase Saturation (Irreducible Water) for Sandstones} (Protection of Argillaceous Fractions)

Rocks containing an argillaceous fraction, i.e. in practice, sandstones where reservoirs are concerned, raise a very delicate problem mentioned in the previous section: during fluid substitutions, it is essential to protect the integrity of the argillaceous minerals. We believe that the only practical solution is to preserve the brine surrounding the argillaceous fractions during the flushings, i.e. the irreducible water $\left(S_{w i}\right)$. After total saturation with brine, the sample must be placed in irreducible saturation with a liquid that is obviously immiscible with water. Fluid substitutions can then be carried out using liquids that are miscible with each other (but always immiscible with water).

The stresses associated with the transmission of a good ultrasonic signal between the measurement heads and the rock sample make it difficult to use semi-permeable membranes that are conventionally used in petrophysics for capillary systems. To achieve displacement in $S_{w i}$, we employ the viscous displacement method: the brine is pushed by a very viscous oil. The viscosity contrast helps to maintain a pressure difference which offsets the capillary pressure between the oil (nonwetting) and the brine (wetting fluid). Viscous displacement is ideal for our problem and is highly efficient: it easily helps to obtain low $S_{w i}$.
In practice, many oils and oil mixtures are available offering a very wide range of viscosities. For very permeable rocks, we use Polyal and, for less permeable rocks, Albelf or Albelf-Soltrol blends. The irreducible brine saturation is calculated by material balance. After the placement of this first nonwetting fluid, fluid substitutions are carried out by miscible displacement of liquids immiscible with water. In practice, we use hydrocarbons: kerosene, heptane, hexane, pentane, etc. If a viscous oil is displaced, this is done with a liquid with much lower viscosity, providing an unfavorable case of miscible displacement, making it necessary to flush a particularly large number of pore volumes (at least twenty in our experiments).

In this case of two-phase saturation, the value to be used for the fluid compressibility $\left(1 / K_{f l}\right)$ is the mean of the compressibilities of the fluids present, weighted by their volumetric fraction (assumption of constant and equal pressure in all the fluid phases). Since the $S_{w i}$ is often very low (less than $10 \%$ ), the values of $K_{f l}$ remain in the range of that of the main liquid. The range of $K_{f l}$ practically available stretches from that of brine to that of pentane. Hence this implies a less favorable situation than in the case of carbonates. Yet the many highly satisfactory experimental results demonstrate that this is irrelevant.

\subsection{Experimental Results: Calculation of $K_{\mathrm{dry}}$ and $K_{\text {grain }}$}

The $P$ and $S$ ultrasonic signals are recorded at each stage of the experiment. The combination of the different pressure levels and saturating fluids means that on the whole, a fairly large body of data are available, which can be interpreted in several steps of increasing complexity. The many cases observed in the laboratory can be grouped around a few main types which helps to simplify the analysis.

\subsection{1 "Ideal" Porous Medium: Sintered Quartz}

In an ideal porous medium, the solid matrix is insensitive to the differential pressure (absence of any grain boundary or microcrack) and the grain size distribution is sufficiently fine and homogeneous to eliminate any scattering effect. In fluid substitution experiments in such a medium, only the effect of the saturating fluid can be observed, without any other "spurious" mechanism. This is the case in practice in sintered quartz (Fig. 4). In this figure (and in the subsequent figures), the acoustic signals have been time-lagged in order to display a "common first break", i.e. the propagation times have been corrected for the velocity variation effect. This considerably simplifies the comparison of the signal shapes. In the case of sintered quartz, once this velocity effect has been eliminated, the signals corresponding to the saturation states with various liquids display very similar shapes 
The quality of the experimental relation $K_{\text {sat }} v s K_{f l}$ is excellent even if the simplest (first break picking) velocity measurement method is employed. Table 2 lists the values of the petroacoustic parameters $\left(K_{\text {dry }}\right.$ et $\left.K_{\text {grain }}\right)$ calculated from regression lines corresponding to the multiple measurements of correlation velocity at fixed differential pressure. These values are surprisingly stable.

These correlation measurements correspond to the following procedure: for a fixed pressure, a reference signal is selected corresponding to a certain saturation. The velocity of this reference is assumed to be known by first break picking (or by another method, like phase velocity, for example) and the velocities calculated by correlation for the other saturation states at this fixed pressure. To overcome the uncertainty on the absolute value of the "reference" velocity, it is important to repeat the calculation by taking each saturation state in succession for reference. By this method of "crossed correlations by pressure level", a large number of relations $K_{\text {sat }} v s K_{f l}$ are obtained, which help to calculate an equivalent number of $K_{\text {dry }}$ and $K_{\text {grain }}$ leading to a statistical estimation of the petroacoustic parameters. These tables of $K_{\text {dry }}$ or $K_{\text {grain }}$ can correspond to regressions which may or may not include the "wet air" and "vacuum" saturation states.

Unfortunately, we have no independent estimate of the bulk modulus of the grains forming the material $\left(K_{\text {grain }}\right)$, which deprives us from an invaluable means of checking.
X-ray diffraction reveals the abundant presence of trydimite, a monoclinic low density (and probably low bulk modulus) variety of silica. The low $K_{\text {grain }}$ measured hence appear to be fairly normal. The experimental results obtained appear to us to be sufficiently consistent to demonstrate the validity of the proposed method.

In the case of natural media, these ideal results are not longer obtained, because two mechanisms in particular can disturb the measurements:

- signal distortion caused by high attenuation; this case is often observed in sandstones under low differential pressure;

- "path dispersion" which is mainly observed in limestones, and which is the main disturbing mechanism.

\subsubsection{Sandstones: Effect of the Effective Stress}

We showed in the first part that propagation velocities in sandstones could be very sensitive to the differential pressure. This also applies for attenuation. Under low differential pressure (5 MPa or less), attenuation can be particularly high. Figure 5, which illustrates a rather general case, shows that the shape of the signal (frequency content) evolves very clearly as a function of pressure. For $S$ waves, the signals could not be recorded for pressures under $5 \mathrm{MPa}$, because of the very poor signal-to-noise ratio. This explains why the petroacoustic results at low pressure (when the $S$ signals could be interpreted!) are extremely mediocre. By contrast, at high pressures, the propagated signals are of good

TABLE 2

Results in GPa of calculations of $K_{\text {grain }}$ and $K_{\text {dry }}$ from experimental lines $K_{\text {sat }} v s K_{f l}$ obtained on sintered quartz by correlation velocities, at different differential pressures and including (at bottom) or excluding (at top) the values corresponding to the "dry" saturation states. The values of the shear modulus $(\mu)$ correspond to means on all the references

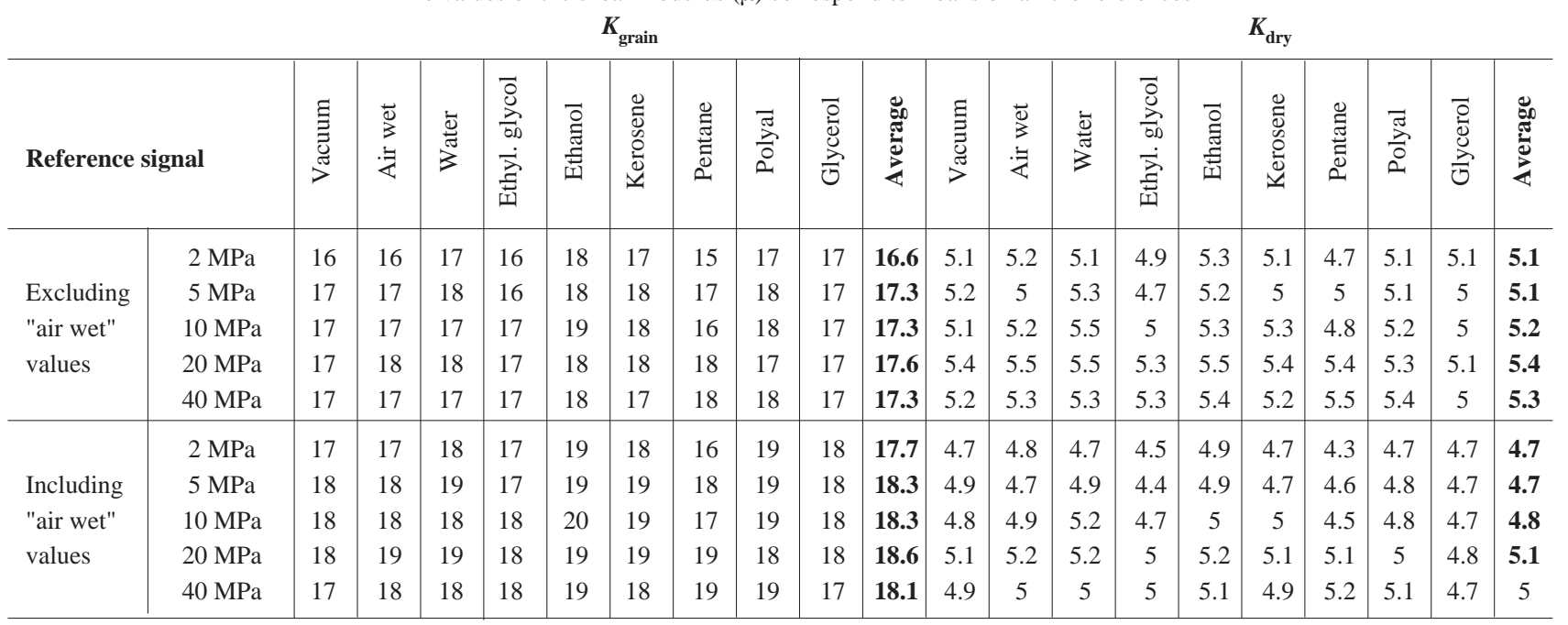

\begin{tabular}{l|c|c|c|c|c}
\hline Differential pressure & $2 \mathrm{MPa}$ & $5 \mathrm{MPa}$ & $10 \mathrm{MPa}$ & $20 \mathrm{MPa}$ & $40 \mathrm{MPa}$ \\
\hline$\mu$ mean & 5 & 5.1 & 5.1 & 5.2 & 5.5 \\
\hline Standard deviation & 0.31 & 0.32 & 0.38 & 0.3 & 0.24 \\
\hline
\end{tabular}


quality and the shape depends very little on the saturating fluid (Fig. 6). The petroacoustic results are good (according to the criterion of $K_{\text {grain }}$ whose value is around $40 \mathrm{GPa}$ for quartz). Table 3 shows that the bulk modulus varies slightly with differential pressure. As we pointed out in section 1, in this clean sandstone, it is mainly the shear modulus that is sensitive to the pressure effect.

Figure 6 shows the results of moduli calculated using phase velocities. Note however, in Figure 7, that for sintered quartz and Fontainebleau sandstone, the phase velocities and first break velocities are very similar (less than $2 \%$ difference). Hence it is not systematically necessary to use the phase velocity method in sandstones.

Even using simple velocity measurement methods (correlation by pressure levels and measurement of references by first break picking), the results on sandstone samples are generally good at high differential pressures, which specifically correspond to those of interest to us in practice. The method proposed is hence highly satisfactory for sandstone reservoirs.

\subsubsection{Limestones: the Problem of Path Dispersion}

The situation is quite different for limestones: we have seen that these rocks often display low Hertz coefficients (weak pressure dependence of velocities). The absence of microcracks, associated with the ease of calcite cementation, makes them virtually immune to the pressure effect. The situation could be construed to be simpler than that for sandstones. This is untrue, because the effects of path dispersion (scattering), discussed earlier, are highly prevalent.

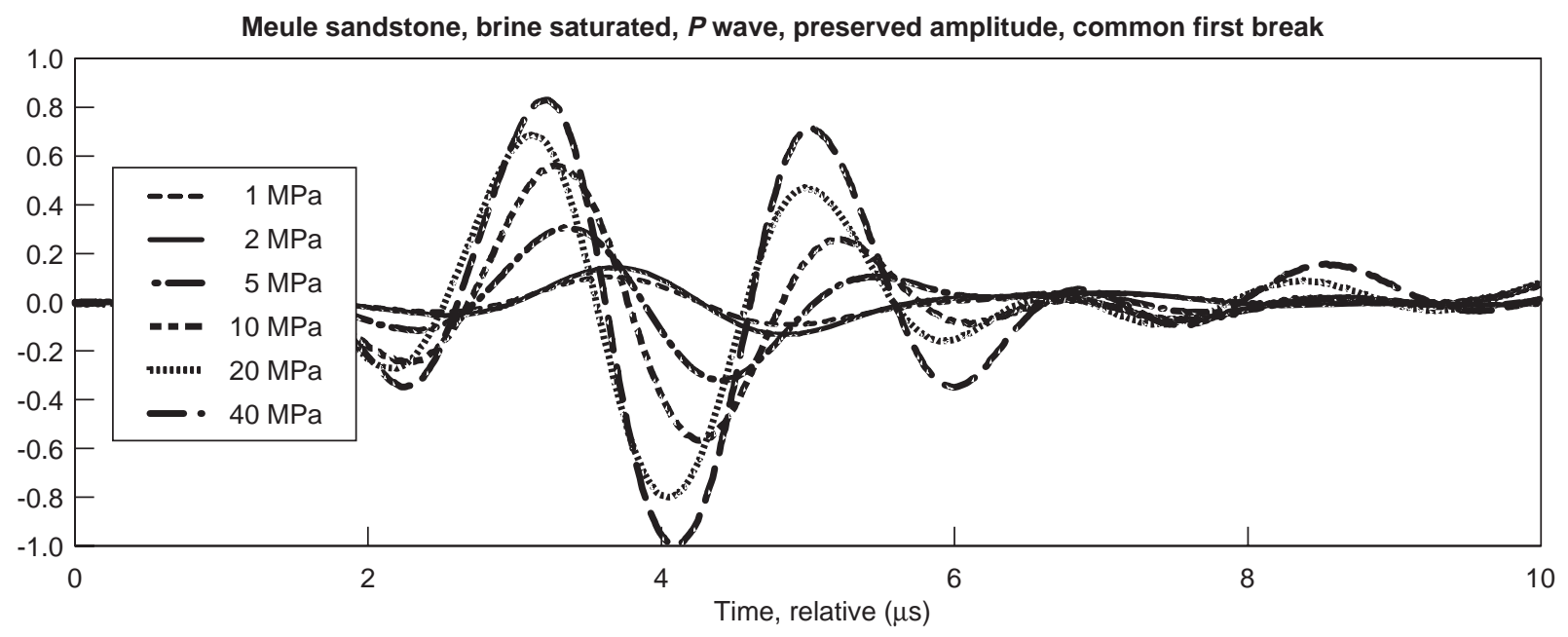

Meule sandstone, brine saturated, $S$ wave, preserved amplitude, common first break

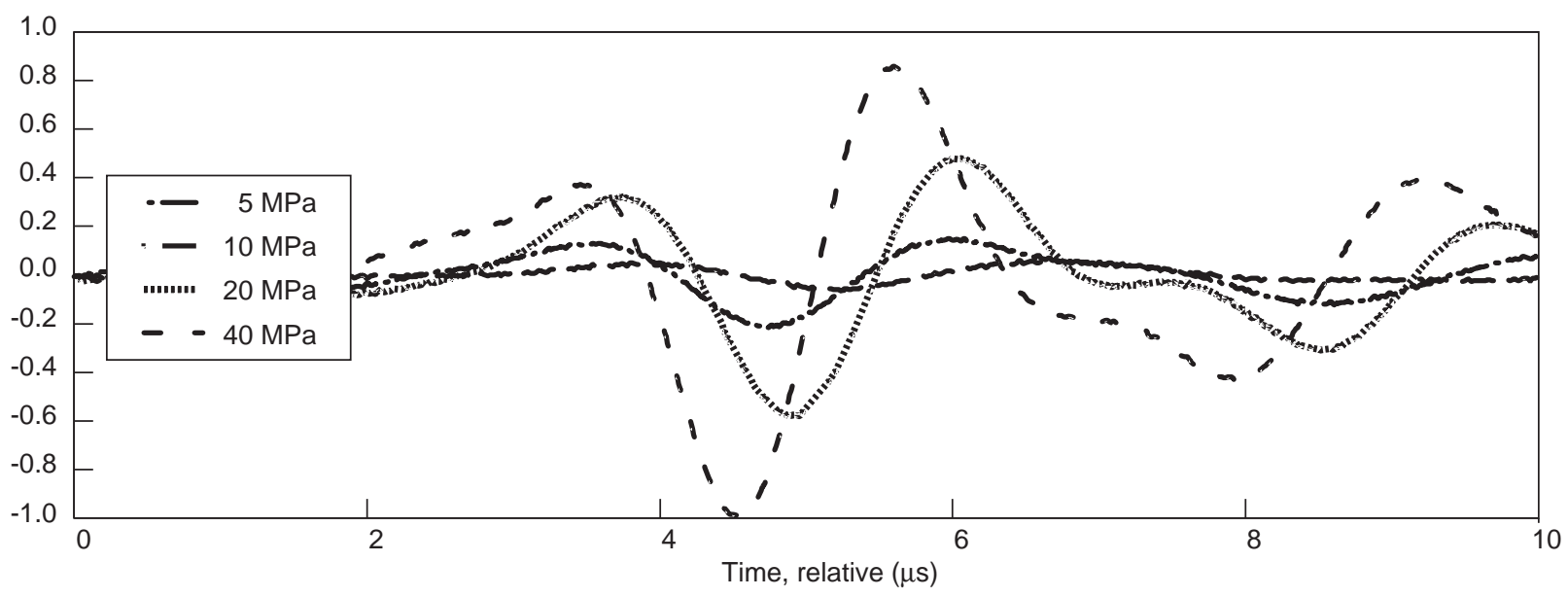

Figure 5

Meule sandstone: $P$ and $S$ waves propagated during a fluid substitution experiment. 
Fontainebleau sandstone, $20 \mathrm{MPa}, \boldsymbol{P}$ wave, preserved amplitude, common first break

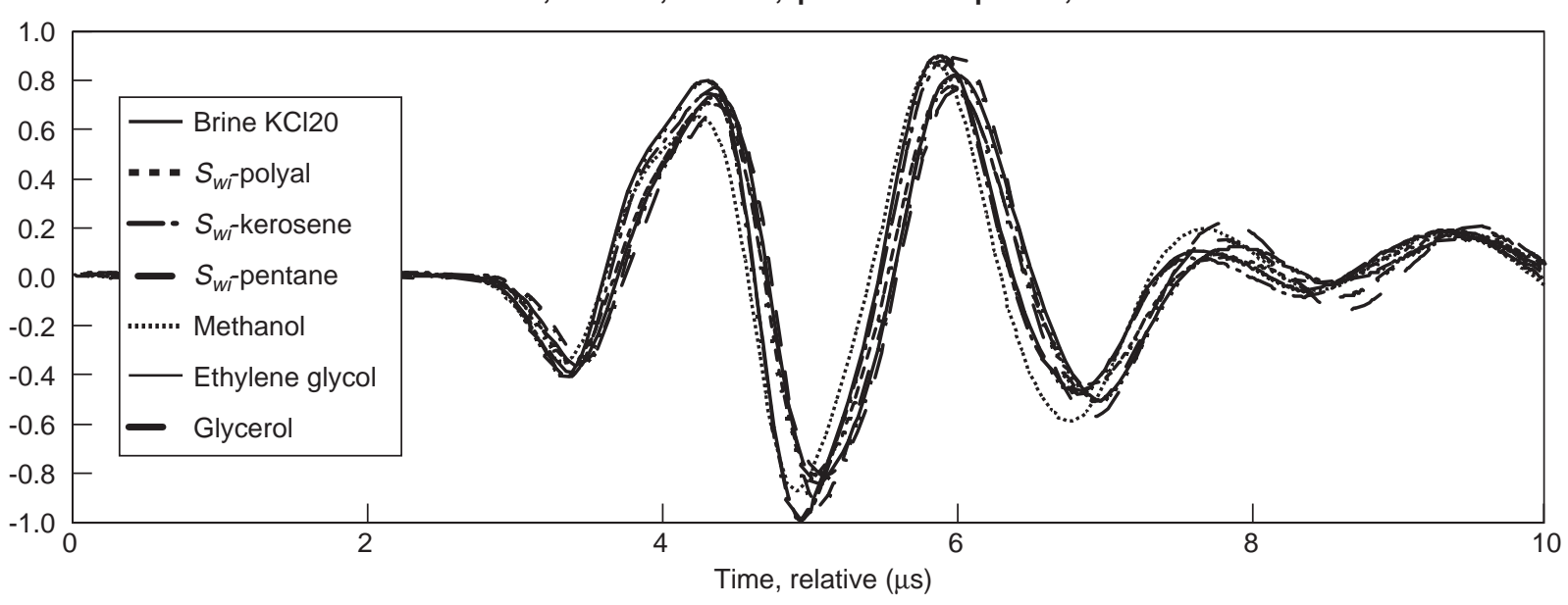

Fontainebleau sandstone, $20 \mathrm{MPa}$, $S$ wave, preserved amplitude, common first break
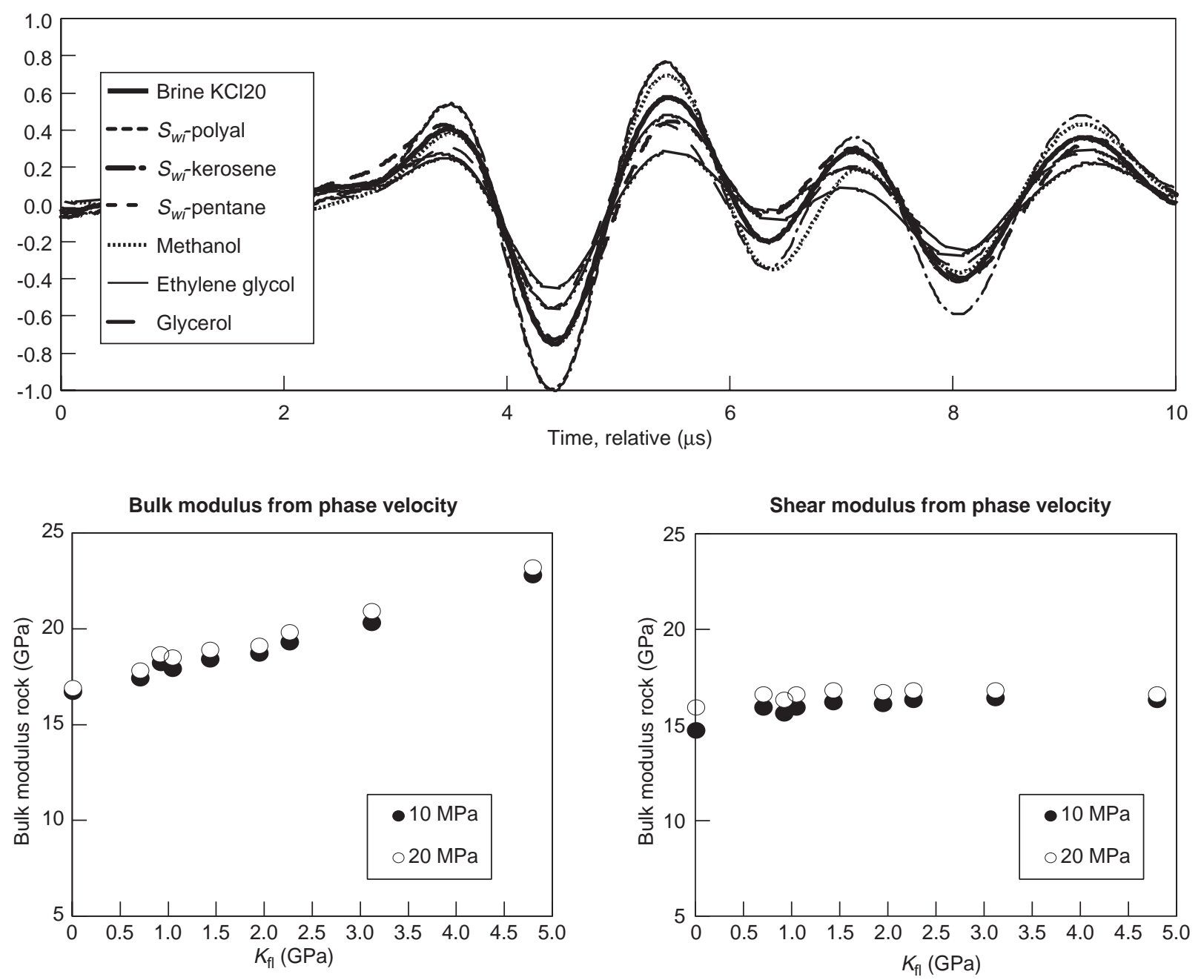

Figure 6

Fontainebleau sandstone: $P$ and $S$ waves propagated during a fluid substitution experiment and relations $K_{\text {sat }}=f\left(K_{f l}\right)$ and $\mu=f\left(K_{f f}\right)$. 
TABLE 3

Results in GPa of calculations of $K_{\text {grain }}$ and $K_{\text {dry }}$ from experimental lines $K_{\text {sat }} v s K_{f l}$ obtained on Fontainebleau sandstone by correlation velocities, at different differential pressures and including (at bottom) or excluding (at top) the values corresponding to the "dry" saturation states.

The values of the shear modulus $(\mu)$ correspond to means on all the references.

\begin{tabular}{|c|c|c|c|c|c|c|c|c|c|c|c|c|c|c|c|c|c|c|c|c|c|}
\hline & & \multicolumn{11}{|c|}{$K_{\text {grain }}$} & \multicolumn{9}{|c|}{$K_{\mathrm{dry}}$} \\
\hline \multicolumn{2}{|c|}{ Reference signal } & \begin{tabular}{l}
$\overrightarrow{0}$ \\
3 \\
. \\
\multirow{2}{*}{}
\end{tabular} & 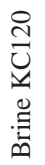 & $\begin{array}{l}\bar{\pi} \\
\frac{\pi}{2} \\
\sum_{1}^{1} \\
n^{2}\end{array}$ & 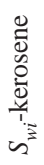 & 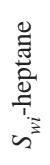 & 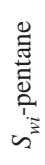 & 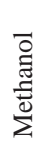 & 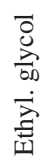 & 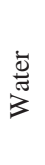 & D্ত & $\begin{array}{l}\overrightarrow{0} \\
\stackrel{0}{*}\end{array}$ & 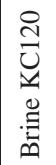 & $\begin{array}{l}\underset{\frac{\pi}{2}}{0} \\
\frac{1}{1} \\
n^{3}\end{array}$ & 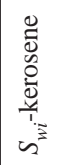 & 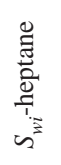 & 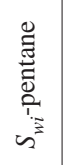 & 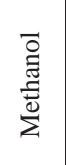 & 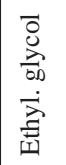 & 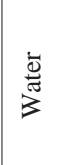 & $\begin{array}{l}\overline{0} \\
\stackrel{0}{0} \\
0\end{array}$ \\
\hline \multirow{5}{*}{$\begin{array}{l}\text { Excluding } \\
\text { "air wet" } \\
\text { values }\end{array}$} & $2 \mathrm{MPa}$ & 39 & 38 & 39 & 31 & 28 & 33 & 31 & 35 & 36 & 36 & 16.7 & 16 & 16.8 & 14.4 & 13.5 & 15 & 14.5 & 15.7 & 16 & 16 \\
\hline & $5 \mathrm{MPa}$ & 35 & 37 & 36 & 33 & 33 & 33 & 30 & 34 & 35 & 36 & 17.1 & 17.6 & 17.5 & 16.4 & 16.3 & 16.4 & 15.1 & 16.6 & 16.9 & 17.3 \\
\hline & $10 \mathrm{MPa}$ & 32 & 32 & 33 & 32 & 32 & 32 & 32 & 33 & 33 & 36 & 17.5 & 17.1 & 17.3 & 17.3 & 17.2 & 17.2 & 17.2 & 17.6 & 17.7 & 18.8 \\
\hline & $20 \mathrm{MPa}$ & 34 & 33 & 35 & 34 & 35 & 35 & 33 & 35 & 35 & 35 & 17.3 & 17.1 & 17.6 & 17.3 & 17.7 & 17.9 & 17 & 17.8 & 17.6 & 18 \\
\hline & $40 \mathrm{MPa}$ & 34 & & 37 & 35 & 35 & 34 & 34 & 35 & 35 & 36 & 17.3 & & 18.5 & 17.9 & 17.8 & 17.6 & 17.4 & 18 & 17.8 & 18.2 \\
\hline \multirow{5}{*}{$\begin{array}{l}\text { Including } \\
\text { "air wet" } \\
\text { values }\end{array}$} & $2 \mathrm{MPa}$ & 43 & 41 & 43 & 33 & 31 & 36 & 34 & 38 & 39 & 39 & 16.7 & 16 & 16.8 & 14.4 & 13.5 & 15 & 14.5 & 15.7 & 16 & 16 \\
\hline & $5 \mathrm{MPa}$ & 37 & 39 & 38 & 35 & 35 & 35 & 31 & 35 & 36 & 37 & 17.1 & 17.6 & 17.5 & 16.4 & 16.3 & 16.4 & 15 & 16.5 & 16.9 & 17.3 \\
\hline & $10 \mathrm{MPa}$ & 34 & 34 & 35 & 34 & 34 & 34 & 34 & 35 & 35 & 38 & 17.5 & 17.1 & 17.4 & 17.3 & 17.2 & 17.2 & 17.2 & 17.7 & 17.7 & 18.8 \\
\hline & $20 \mathrm{MPa}$ & 35 & 35 & 36 & 35 & 36 & 37 & 34 & 37 & 36 & 37 & 17.3 & 17.1 & 17.6 & 17.3 & 17.7 & 17.9 & 17 & 17.8 & 17.6 & 18 \\
\hline & $40 \mathrm{MPa}$ & 35 & & 38 & 36 & 36 & 36 & 35 & 37 & 36 & 37 & 17.3 & & 18.5 & 17.9 & 17.8 & 17.6 & 17.4 & 18 & 17.8 & 18.2 \\
\hline
\end{tabular}

\begin{tabular}{l|c|c|c|c|c}
\hline Effec. pressure & $2 \mathrm{MPa}$ & $5 \mathrm{MPa}$ & $10 \mathrm{MPa}$ & $20 \mathrm{MPa}$ & $40 \mathrm{MPa}$ \\
\hline$\mu$ mean & 14.3 & 15.5 & 16.4 & 16.9 & 17.2 \\
Standard devia. & 1.45 & 0.71 & 0.63 & 0.21 & 0.18 \\
\hline
\end{tabular}

The most evident consequence of this scattering is the variability, as a function of saturating fluid, of the shape of the transmitted $P$ wave signals. Figure 8 shows the variation in the pseudo-period between the saturated states with glycerol and with bromoform. A progressiveness in the variation in the shape of the signals is also observed between these two saturation states. This evolution matches that of the wave propagation velocities in the saturating liquid (see Table 1), because the approximate order is: glycerol, ethylene glycol, water, ethanol, pentane and bromoform. Note that the important parameter is the velocity and not the impedance, because the two extreme saturating liquids of our list are glycerol and bromoform, which correspond to the two highest impedances.

The way to contend with these effects, at least partially, is to use the phase velocities. Figure 9 provides a comparison of the phase and first break velocities in a moderate case of "path dispersion". It may be observed that the difference between the two velocities is 7 to $10 \%$, with the phase velocity obviously being the lower. But above all, the difference is inversely proportional to the wave propagation velocity in the saturating fluid ( $7 \%$ for glycerol, up to $10 \%$ for bromoform). For $S$ waves, there is no fluid effect. The fluctuation about the ratio 1 corresponds to the uncertainty of the first break picking, which is always fairly high for $S$ waves.

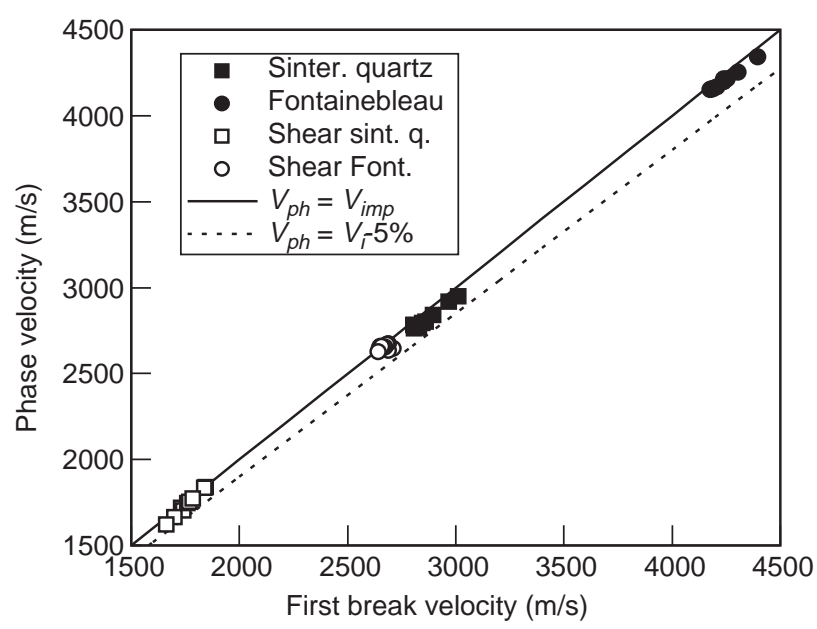

Figure 7

Comparaison of first break picking velocities and phase velocities in sintered quartz and Fontainebleau sandstone.

Tables 4 and 5 show two examples of comparisons of results obtained for different velocity calculation methods. Table 4 gives the mean of several measurements on the same sample of Estaillades limestone. The low sensitivity of the result for $\mathrm{m}$ to the measurement method can be observed. For 
S7, $10 \mathrm{MPa}, \boldsymbol{P}$ wave, preserved amplitude, common first break

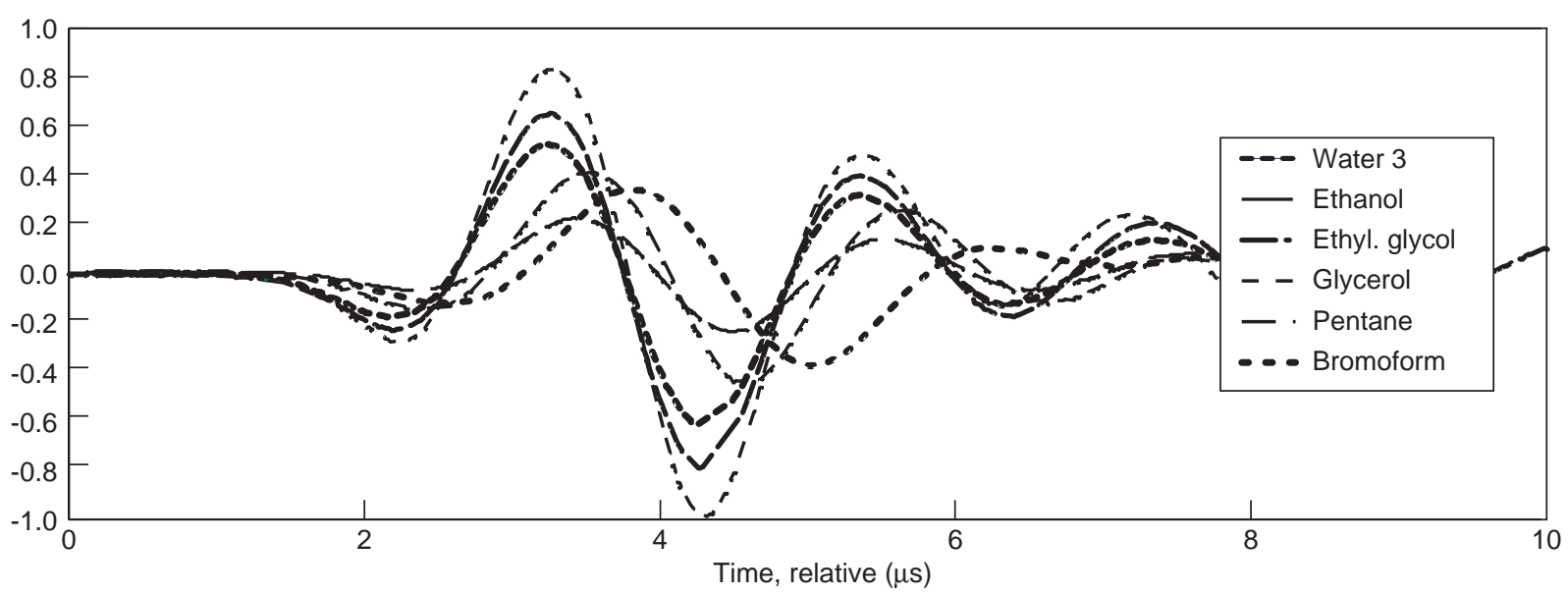

\begin{tabular}{|lr|}
\hline Bromoform & $945 \mathrm{~m} / \mathrm{s}$ \\
Pentane & $1070 \mathrm{~m} / \mathrm{s}$ \\
Ethanol & $1190 \mathrm{~m} / \mathrm{s}$ \\
Water & $1500 \mathrm{~m} / \mathrm{s}$ \\
Ethyl. glycol & $1707 \mathrm{~m} / \mathrm{s}$ \\
Glycerol & $1950 \mathrm{~m} / \mathrm{s}$ \\
\hline
\end{tabular}

S7, $10 \mathrm{MPa}, P$ wave, preserved amplitude, common first break

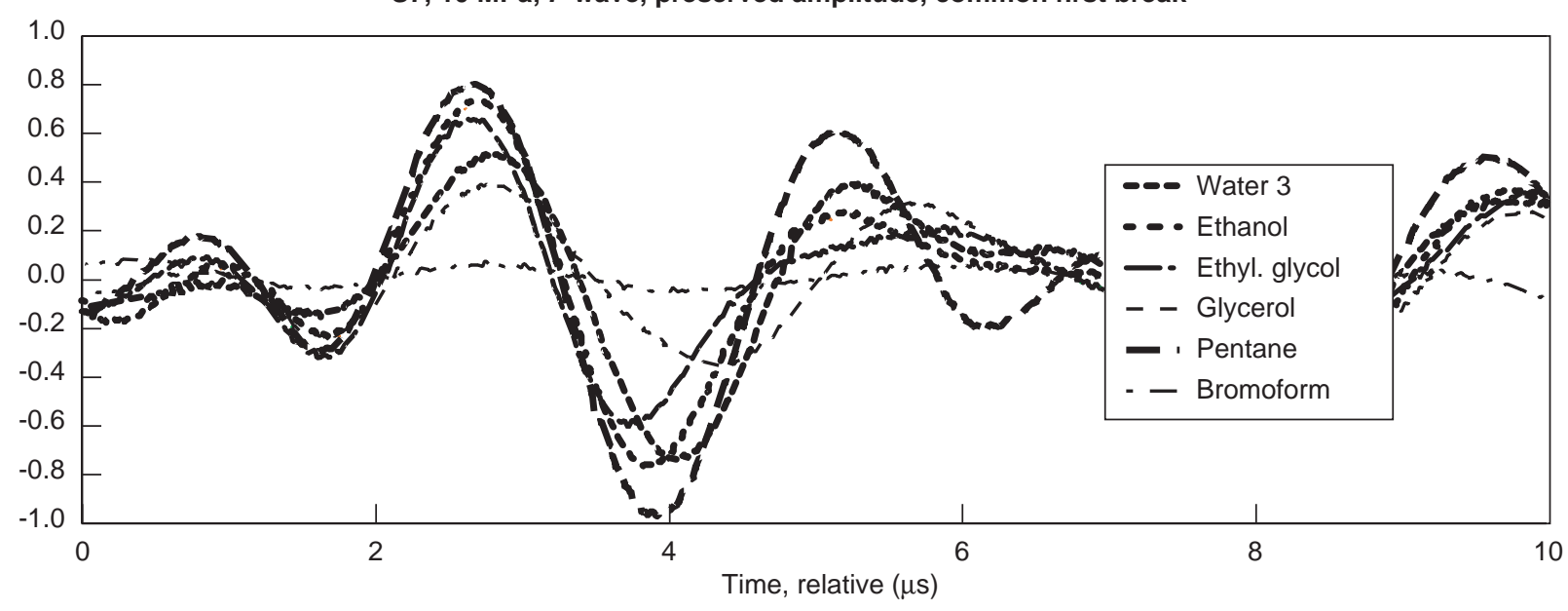

Figure 8

Estaillades limestone: $P$ and $S$ waves propagated for various saturation states.

a large series of measurements, the picking uncertainties are statistically compensated. By contrast, for $K_{d r y}$, the differences are wide. In limestones, the bulk modulus of the crystal (calcite) forming the skeleton of the rock is well known (about $70 \mathrm{GPa}$ ). Hence the criterion of $K_{\text {grain }}$ can be used as a means of checking: the results for phase velocity processing are better. thee results on Menerbes limestone (Table 5), corresponding to a more conventional experiment, confirm these observations. Note that the difference in $\mu$ is much wider than in the previous case. This appears to correspond to the general case.

The petroacoustics of limestone reservoirs raises difficult problems and merits further development. The use of phase velocities and of the value of $K_{\text {grain }}$ derived as a means for checking quality enable us to obtain much more reliable results than those obtained by conventional methods. 
Estaillades limestone $P$ wave

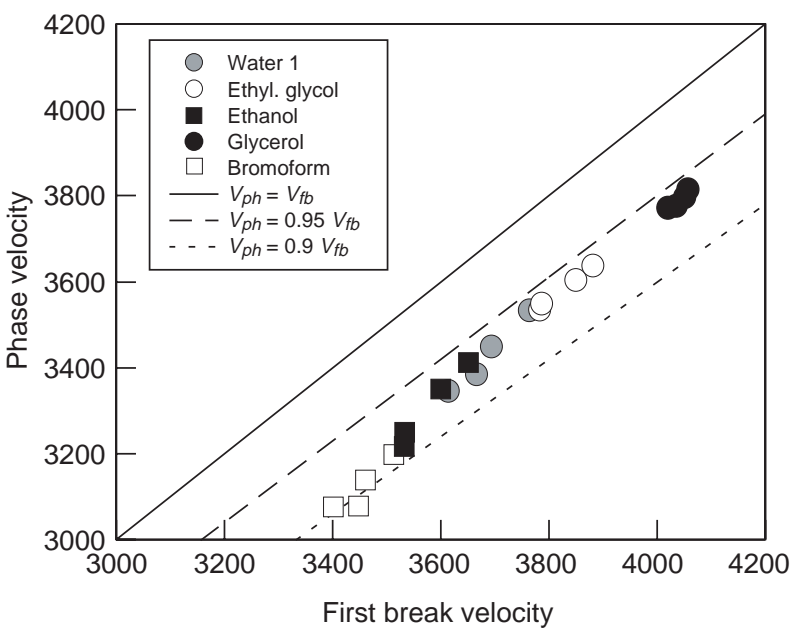

Estaillades limestone $S$ wave

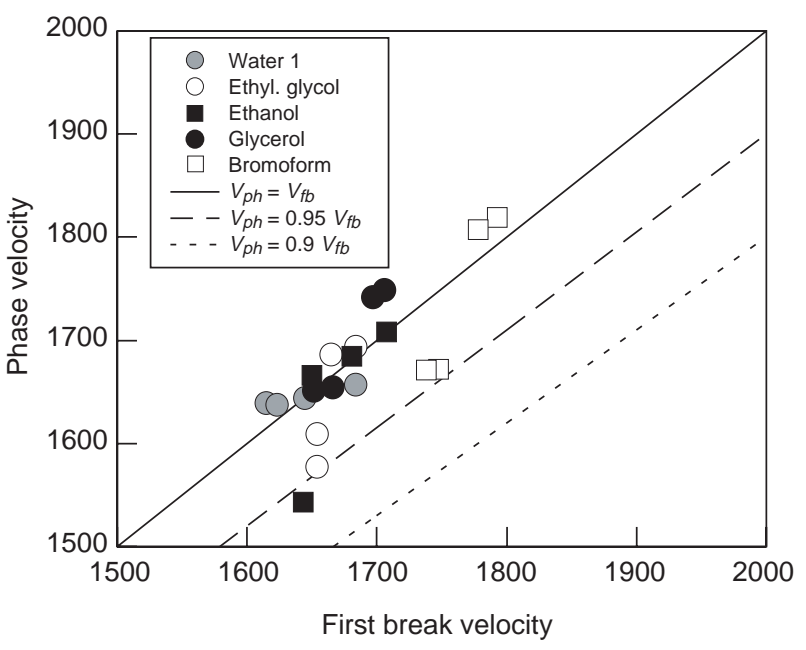

Figure 9

Comparison of phase velocities and first break picking velocities in Estaillades limestone.

\subsection{Conclusions on Measurements by Fluid Substitution: an Original and Reliable Method}

The method presented for the estimation of the fluid substitution effects, based on the experimental measurement of the relation $K_{\text {sat }}=f\left(K_{f l}\right)$, a linear approximation of the Gassmann formula, is original and simple in principle. The possibility of deriving a value of $K_{\text {grain }}$, a parameter that is independently known for rocks of simple composition (limestone, clean sandstone), significantly enhances the reliability of the method.

\section{TABLE 4}

Estaillades limestone (S7), comparison of values obtained for $\mu, K_{\mathrm{dry}}$ and $K_{\text {grain }}$ as a function of the method used to measure the velocities. The moduli are expressed in GPa. The regression values are calculated on 20 saturation states (15 different fluids or two-phase pairs)

\begin{tabular}{c|c|c|c|c|c}
\cline { 3 - 6 } \multicolumn{2}{c|}{} & $\mathbf{1} \mathbf{~ M P a}$ & $\mathbf{2} \mathbf{M P a}$ & $\mathbf{5} \mathbf{~ M P a}$ & $\mathbf{1 0} \mathbf{M P a}$ \\
\hline \multirow{2}{*}{$\begin{array}{c}\text { First } \\
\text { break }\end{array}$} & $\mu \mathrm{GPa}$ & 5.8 & 5.9 & 6.1 & 6.3 \\
\hline \multirow{2}{*}{ Correlation } & Stand. dev. & 0.2 & 0.18 & 0.15 & 0.12 \\
\hline \multirow{2}{*}{ Phase } & $\mu \mathrm{GPa}$ & & 5.9 & 6.1 & 6.3 \\
& Stand. dev. & & 0.16 & 0.14 & 0.1 \\
\hline & $\mu \mathrm{GPa}$ & 5.5 & 5.9 & 6.2 & 6.3 \\
& Stand. dev. & 0.34 & 0.16 & 0.25 & 0.21 \\
\hline
\end{tabular}

\begin{tabular}{c|c|c|c|c|c}
\cline { 3 - 6 } \multicolumn{2}{c|}{} & $\mathbf{1} \mathbf{M P a}$ & $\mathbf{2} \mathbf{M P a}$ & $\mathbf{5} \mathbf{M P a}$ & $\mathbf{1 0} \mathbf{M P a}$ \\
\hline \multirow{2}{*}{$\begin{array}{c}\text { First } \\
\text { break }\end{array}$} & $K_{\text {dry }}$ & 16.1 & 16.3 & 17 & 17.7 \\
& $K_{\text {grain }}$ & 115 & 116 & 116 & 104 \\
\hline \multirow{2}{*}{ Correlation } & $K_{\text {dry }}$ & & 15.7 & 16.9 & 17.3 \\
& $K_{\text {grain }}$ & & 193 & 135 & 128 \\
\hline \multirow{2}{*}{ Phase } & $K_{\text {dry }}$ & 12.3 & 12.3 & 13.8 & 14.5 \\
& $K_{\text {grain }}$ & 79 & 89 & 64 & 69 \\
\hline
\end{tabular}

TABLE 5

Menerbes limestone (S8). comparison of values obtained for $\mu, K_{\mathrm{dry}}$ and $K_{\text {grain }}$ as a function of the method used to measure the velocities. The moduli are expressed in GPa. The regression values are calculated on 5 saturation states (excluding the "vacuum" state)

\begin{tabular}{c|c|c|c|c|c}
\cline { 3 - 6 } \multicolumn{2}{c|}{} & $\mathbf{1 ~ M P a}$ & $\mathbf{2} \mathbf{M P a}$ & $\mathbf{5} \mathbf{~ M P a}$ & $\mathbf{1 0} \mathbf{~ M P a}$ \\
\hline \multirow{2}{*}{$\begin{array}{c}\text { First } \\
\text { break }\end{array}$} & $\mu \mathrm{GPa}$ & 6.7 & 6.8 & 7.1 & 7.2 \\
& Stand. dev. & 0.34 & 0.24 & 0.2 & 0.2 \\
\hline \multirow{2}{*}{ Correlation } & $\mu \mathrm{GPa}$ & & 6.8 & 7.1 & 7.2 \\
& Stand. dev. & & 0.28 & 0.21 & 0.19 \\
\hline \multirow{2}{*}{ Phase } & $\mu \mathrm{GPa}$ & 5.8 & 5.9 & 6.1 & 6.2 \\
& Stand. dev. & 0.24 & 0.19 & 0.13 & 0.11 \\
\hline
\end{tabular}

\begin{tabular}{c|c|c|c|c|c}
\cline { 3 - 6 } \multicolumn{2}{c|}{} & $\mathbf{1 ~ M P a}$ & $\mathbf{2} \mathbf{M P a}$ & $\mathbf{5} \mathbf{~ M P a}$ & $\mathbf{1 0} \mathbf{~ M P a}$ \\
\hline \multirow{2}{*}{$\begin{array}{c}\text { First } \\
\text { break }\end{array}$} & $K_{\text {dry }}$ & 12.6 & 13 & 13.4 & 14 \\
\hline \multirow{2}{*}{ Correlation } & $K_{\text {grain }}$ & 104 & 89 & 85 & 82 \\
\hline \multirow{2}{*}{ Phase } & $K_{\text {dry }}$ & & 12.3 & 13 & 13.5 \\
& $K_{\text {grain }}$ & & 210 & 137 & 127 \\
\hline & $K_{\text {dry }}$ & 8.9 & 9.4 & 10.2 & 10.8 \\
& $K_{\text {grain }}$ & 91 & 82 & 71 & 66 \\
\hline
\end{tabular}


A compromise between measurement cost and reliability leads to a variation in the choice of fluids as well as the measurement that is to be used according to the type of reservoir. We resume these points in the general conclusion, including the effect of differential pressure.

\section{CONCLUSIONS}

\subsection{A Different Practical Approach for Sandstones and Limestones}

\subsubsection{In Sandstones: Importance of the Hertz Coefficient; Need for Two-Phase Saturation, But Easy Measurement Processing}

\section{Differential Pressure Effect}

The most evident petroacoustic characteristic of sandstones is their sensitivity to differential pressure. Very often, parameters measured at low pressure are completely different from those measured at the high differential pressures prevailing in the reservoirs. This point is well known but always deserves to be repeated: measurements under confining pressure are necessary in all cases.

In the laboratory, it is easy to determine the Hertz coefficient. On the other hand, it is very difficult to derive an accurate idea of the representativity of such a measurement in relation to reservoir conditions. During coring, the sudden relaxation of in situ stresses can cause mechanical microdefects, which significantly increase the Hertz coefficient. Another point worth considering, and liable to act in the same direction, is the possible alteration of argillaceous or micaceous minerals. The value of the Hertz coefficient measured in the laboratory is hence often a value "from above". Yet it can be used to make a preliminary estimate of the pressure effect. As a rule, this effect is sufficiently weak to preclude the need for complementary investigations. In the case of overpressurized reservoirs and underground storage facilities at "shallow" depth, where pressure effects may be significant, it could be possible to work on surface (unaltered) analogues for which stress relaxation, which is spread over geological time scales, has left very few traces.

\section{Fluid Substitution Effect}

In sandstones with normal grain size distribution, where scattering effects can be discounted, the measurement of Gassmann coefficients, at high differential pressures (the only ones of practical interest), raises no particular problems. The only important precaution to be observed is to use liquids that do not disturb the argillaceous minerals (and weathered feldspars). Apart from the case of perfectly clean sandstones, it is preferable by far to preserve some irreducible saturation with brine $\left(S_{w i}\right)$ and hence to work with twophase saturation (brine/hydrocarbons).

Also apart from clean sandstones, for which the mineralogical nature of the crystals forming the rock is well known (quartz, $K_{\text {grain }} \approx 39 \mathrm{GPa}$ ), the precise composition of the rock is generally unknown. This removes the benefit of the strong checking parameter represented by the derived value of $K_{\text {grain }}$. In sandstones, however, the measurements are of sufficient quality for the estimated value of $K_{\text {grain }}$ to be considered as a petroacoustic parameter that is useful in calculations.

\subsubsection{In Limestones: Weak Influence of Pressure, Simplicity of Single-Phase Substitutions but Difficulty of Processing Associated with "Path Dispersion"}

The situation for limestone reservoirs is nearly the opposite, because the pressure effect is usually very slight, while velocity measurements are complicated by "path dispersion", whereas $K_{\text {grain }}$ is well known (calcite).

\section{Differential Pressure Effect}

In pure limestones, the problem of the pressure effect arises only very seldom: the Hertz coefficients are sufficiently low. The only exceptions to our knowledge concern crystalline limestones, in which microcracks and inter-crystalline contacts can play a role, with the extreme example provided by certain marbles (which are not petroleum reservoirs). Crinoidal limestones, due to the importance of the large syntaxial sparites, can also exhibit a significant sensitivity to differential pressure. In practice, in limestone reservoirs, one merely checks that the pressure effect is slight.

In the case of dolomitization, however, the situation is completely different. Dolomite generally occurs in the form of small rhombohedral crystals and the mechanical properties of the inter-crystalline contacts are highly sensitive to the stress state. Hence considerable pressure effects can be observed, which are dealt with as in the case of sandstones.

\section{Fluid Substitution Effect}

In limestones, which usually contain no clay, fluid substitution experiments are facilitated by the possibility of singlephase flushing by liquids of varied bulk modulus. The range of $K_{f l}$ convenient for the laboratory is between $0.7 \mathrm{GPa}$ (pentane) and 3.2 GPa (ethylene glycol), and even $4.8 \mathrm{GPa}$ if the rock is sufficiently permeable to allow flushing with glycerol. Hence these are ideal conditions for obtaining significant $K_{\text {sat }}=f\left(K_{f l}\right)$ relations. Besides, the $K_{\text {grain }}$ modulus is well known (calcite, $K_{\text {grain }} \approx 70 \mathrm{GPa}$ ). 
The advantage offered by this real experimental asset is unfortunately diminished by the difficulty of processing the signals due to the mechanism of "path dispersion" corresponding to scattering on heterogeneities of nonnegligible size compared with the wavelength. These heterogeneities (no doubt associated with the complex diagenesis of limestones) are omnipresent but not always detectable by a conventional petrographic study. In fact, the characteristic size of these heterogeneities is not necessarily connected with the grain size distribution of the patterned elements present in the limestone.

This "path dispersion", which, as we may observe, displays a close relationship to the "secondary porosity" effect of the log specialists, seriously complicates the experimental study of the petroacoustics of limestone rocks. The use of phase velocities in processing the transmitted signals is very likely the safest means to help solve this difficulty. The prior knowledge of $K_{\text {grain }}$ provides an excellent means to check the results, which considerably facilitates interpretation.

\subsection{Need for Statistical Representativity of Measurements: Towards a Petroacoustic "Rock-Typing"}

In processing petrophysical results, as reliable as the measurements may be-and we believe that this is the case for the method presented here-statistical representativity is an absolute imperative. This representativity can be obtained by the combination of several approaches:

- by performing measurements on a sufficient number of samples;

- by only using representative samples; these samples must obviously meet evident criteria of homogeneity, but they must be selected to clearly represent the different petrophysical facies existing in the reservoir ("rock-types");

- by always striving to connect the petrophysical results with the petrographic features of the rocks analyzed, to clearly understand the cause of any anomalies. This is the safest means to forestall "petrophysical" errors which, in practice, are even more harmful than the absence of measurements!

For applications of the Gassmann formula, the four parameters characterizing the rock are porosity $(\phi)$, shear modulus $(\mu)$, drained bulk modulus $\left(K_{\text {dry }}\right)$ and bulk modulus $\left(K_{\text {grain }}\right)$ of the the crystal making up the solid matrix of the rock. For a reservoir, the porosity is assumed to be known and the knowledge of $K_{\text {grain }}$ directly depends on the accuracy of the lithological determination. In the case of carbonates, the determination of $K_{\text {grain }}$ should not raise any particular problem, except for heterogeneous limestone/dolomitic systems. In the case of sandstones, the situation is more problematic because minerals with very low $K_{\text {grain }}$ (clays, micas and weathered feldspars) may have a substantial effect even if their content is moderate.
The two remaining parameters, $\mu$ and $K_{d r y}$, are elastic parameters in the usual sense of the term. The value of these two moduli is closely linked to the porosity (obviously the same types of relation apply as a function of $\phi$ as for velocities). Hence the approach is to use $\phi$ as a standardization parameter and to define the petroacoustic facies ("rocktype") characterized by a specific $K_{d r y}, \mu=\mathrm{f}(\phi)$ relation. The combined use of logs and laboratory measurements, could make it possible to define the existing petroacoustic facies at every point of the reservoir. Once this description is ideally achieved, it would be possible to calculate, for the entire reservoir, the effect on the seismic characteristics of a variation in pressure and saturating fluid, and thereby to estimate the feasibility of a seismic monitoring operation.

But even more pragmatically speaking, petroacoustic "rock-typing" would offer an immediate advantage in certain cases. The pressure and fluid substitution effects may be very tenuous in many reservoirs. In these reservoirs, the semiquantitative approach based on an analysis, initially empirical, of the variation in seismic attributes, is the only conceivable alternative for the time being. We know from past experience that this type of purely differential approach sometimes helps to detect extremely weak effects. The interpretation of such signals demands recognition of the possible particular sensitivity of the petroacoustic "rocktype" to the mechanism concerned, and hence the identification of the geographic distribution of the "rocktypes" in the reservoir. This approach will undoubtedly be unavoidable in many cases of calcareous reservoirs.

\section{ACKNOWLEDGEMENTS}

This work was carried out at the Rock Physics Laboratory of Institut français du pétrole, with the help of Michel Masson, to whom our warmest thanks. Part of the work benefited from European financial aid in connection with the SACS2 project (Geological Sequestration of $\mathrm{CO}_{2}$ ) and the FSH (in collaboration with Gaz de France). The PV-SV database that we mentioned in section 1 obtained financial support from ARTEP for its development.

\section{REFERENCES}

Biot, M.A. (1941) General theory of three-dimensional consolidation. J. Applied Phys., 12, 155-164.

Birch, F. (1960) The velocity of compressional waves in rocks to 10 kilobars. Part I., J. Geophys. Res., 65, 1083-1102. Part II, J. Geophys. Res., 66, 2199-2224.

Bourbié, T., Coussy, O. and Zinszner, B. (1987) Acoustics of Porous Media, Technip and Gulf Publishing.

Cadoret, T., Marion, D. and Zinszner, B. (1995) Influence of frequency and fluid distribution on elastic wave velocities in partially saturated limestones. J. Geophys. Res., 100, B6. 
Gassmann, F. (1951) Uber die elastizitatporosen medien. Vierteljahrsschrift der Naturforschenden Gesellshaft in Zurich, 96, 1-23.

Lucet, N., and Zinszner, B. (1992) Effects of heterogeneities and anisotropy on sonic and ultrasonic attenuation in rocks. Geophysics, 57, 8, 1018-1028.

Mavko, G., Mukerji, T. and Dvorkin, J. (1998) Rock Physics Handbook, Cambridge University Press.

Nes, O.M., Holt, R.M. and Fjaer, E. (2000) The reliability of core data as imput to seismic reservoir monitoring studies. SPE, 65180.
Rasolofosaon, P. and Zinszner, B. (2002) Vérification expérimentale de la formule de Gassmann dans les calcaires poreux. Oil and Gas Science and Technology - Revue de l'Institut français du pétrole, 57, 2, 129-138.

Tarif, P. (1986) Mesure de l'atténuation des ondes compressionnelles ultrasoniques dans les roches. Thèse, université Paris VII.

Walsh, J.B. and Brace, W.F. (1966) Cracks and pores in rocks. Proc. 1st Congress Int. Soc. of Rock Mechanics, Lisbon, 1, 643646.

Final manuscript received in August 2003 